\title{
The function of face gestures and head movements in spontaneous humorous communication
}

\author{
Marta Buján \\ Universidad de Valladolid \\ marta.bujan.navarro@gmail.com
}

\begin{abstract}
This paper assesses the results of a multimodal analysis of humorous instances found in a collection of 14 interviews from The Late Show with Stephen Colbert. The interviews have been imported and annotated in ELAN for head movements and face gestures. Only the interviewees' remarks are studied in order to ensure the analysis of spontaneous speech, avoiding mostly pre-scripted host's comments and questions. The results demonstrate that there are no gestures consistently and recurrently paired with humour. Therefore, none of the multimodal cues found in the sample can be considered markers of humour. Furthermore, the functions of gestures identified are consistent with the uses reported in previous multimodal studies of humorous and non-humorous communication found in the literature.
\end{abstract}

Keywords: humour, multimodal markers, spontaneous speech, face gestures, head movements.

\section{Introduction}

Face-to-face interaction is inherently multimodal. Multimodal analyses bring in information conveyed through different modalities, which are semiotic resources with meaning potential, i.e., affordances (Adami 2016), such as gesture, gaze, prosody, posture, etc. (Forceville 2016). A multimodal perspective assumes that all these modalities, and crucially, how they interplay, contribute to communication (Kress \& van Leuween 2001; Adami 2016). Therefore, a comprehensive account of communication can only be achieved through careful exploration of how these modalities operate and relate to each other.

Modalities belong to different systems of representation, and they translate into actions which mediate between the concrete and the abstract. Modalities are complex cultural tools, to the extent that they are socially acquired or learnt and used in interaction (Norris 2013). Nonreferential gestures and body movements can have different functions. They help to organise turn-taking (Mondada 2013); they serve to mark constructive action (2012) both as gestures and in signing (they can have discursive value, punctuating, linking, and emphasising parts of speech (McNeill 1992: 15, 16) or introducing new topics (Kendon 2004), and are essentially pragmatic (Cienki 2013). The gestural movements of the hands and arms are probably the most studied co-speech gestures (Wagner et al. 2014), with fewer studies on head or face 
expressions (Hadar et al. 1985; Poggi \& Pelachaud 1998; McClave 2000; Kendon 2002; Lee \& Marsella 2010; Kousidis et al. 2013; Ishi et al. 2014; Tabacaru 2014; etc.).

Research has taken an interest in studying how, and if, humour is multimodally marked, in order to establish whether there are certain gestures, face movements, changes in gaze, intonation or prosody patterns which are invariably associated with humour (Attardo et al. 2003; Attardo, Pickering \& Baker 2011; Tabacaru 2014). Many studies have been conducted on the markers of irony or sarcasm, with conflicting results (Attardo et al. 2003; Attardo, Pickering \& Baker 2011; Attardo, Wagner \& Urios-Aparisi 2011). For the purposes of this research, irony and sarcasm are considered types of humour, although this is contested by some authors (Dynel 2009). Irony has traditionally been defined as the opposite of what is literally expressed, whereas sarcasm is considered to be a more aggressive form of irony, with a clear target criticised (Attardo 2000). Less attention has been devoted to analysing markers of non-ironical humour. In addition, most of the literature is limited to staged humour, with just a handful of studies focusing on spontaneous humour (e.g. Flamson et al. 2011; Attardo, Pickering \& Baker 2011).

This article takes a step towards filling that gap. It assesses how gestures and speech interplay in the production of spontaneous humorous utterances in English, focusing specifically on co-speech spontaneous face gestures and head movements. An analysis of manual gestures had to be discarded, as there was not always a clear shot of the hands in the videos collected. My research is novel insofar as it looks into humour produced in spontaneous communication, and includes all types of humour arisen in the conversations analysed. What follows is an in-depth analysis of the functions of the head and face gestures most frequently found in the sample under study. The first section is devoted to facial displays, focused on raised eyebrows and smile/laughter, followed by a section on head movements, with special emphasis on tilts, nods, shakes, and turns.

\section{Sample and method}

The sample includes 14 interviews from The Late Show with Stephen Colbert. The choice of show has been determined by the fact that, typically, late night shows allow for humorous instances to occur more frequently than other type of shows. Only the interviewee's speech is considered for the analysis, to ensure that it is spontaneous, avoiding mostly pre-scripted or rehearsed host's speech. Interviews were randomly selected. An equal number of men and women are represented in the sample (cf. Table 1). All interviews are freely available on Youtube. The videos were first captured and downloaded in mp4 format from The Late Show with Stephen Colbert YouTube channel using aTubeCatcher (version 3.8.9325 DsNet Corp. 2017). They were subsequently imported in ELAN, version 5.1 (Max Plank Institute for Psycholinguistics 2017), creating one file per interview.

The sample contains 103.83 minutes of interviews, out of which 109 humorous utterances were identified, using laughter in the audience as a criterion. The interviews were imported into ELAN, version 5.1 (Max Plank Institute for Psycholinguistics 2017), where humorous utterances were transcribed and annotated on five tiers: transcription, humour type (Feyaerts 2013; Tabacaru 2014), underlying construal mechanism (Croft \& Cruse 2004), gestures, and prosody. Both the prosodic and cognitive analysis are reported elsewhere (Buján forthcoming). For the annotation of humour types (cf. Table 3 and Fig. 1), I have followed the classification used in the Corinth corpus (Feyaerts et al. 2010; Feyaerts 2013; Tabacaru 2014). The controlled vocabulary used for coding is included in Table 2. Table 3 shows the humour types identified in the sample and their number of occurrences. 
Table 1. Interviews in the sample.

\begin{tabular}{|c|c|c|c|c|c|c|c|}
\hline Interviewee & Gender & Age & $\begin{array}{l}\text { Ethnic } \\
\text { back. }\end{array}$ & $\begin{array}{l}\text { Intervie } \\
\text { w (s.) }\end{array}$ & $\begin{array}{l}\text { Humorous } \\
\text { instances } \\
\text { (n) }\end{array}$ & $\begin{array}{c}\text { Humorous } \\
\text { instances } \\
\text { (seconds) }\end{array}$ & Episode/season date \\
\hline Alec Baldwin & Male & 60 & White & 432,030 & 13 & 43,055 & $\begin{array}{c}\text { Episode } 130(\mathrm{~S} 2) \\
18 / 4 / 2017\end{array}$ \\
\hline Alison Janney & Female & 58 & White & 445,262 & 6 & 29,206 & $\begin{array}{c}\text { Episode134 (S2) } \\
24 / 04 / 2017\end{array}$ \\
\hline Amy Schumer & Female & 36 & White & 514,597 & 12 & 38,495 & $\begin{array}{c}\text { Episode } 140(\mathrm{~S} 2) \\
2 / 05 / 2017\end{array}$ \\
\hline Condola Rashad & Female & 31 & Black & 389,859 & 4 & 17,430 & $\begin{array}{c}\text { Episode } 106(\mathrm{~S} 2) \\
2 / 3 / 2017\end{array}$ \\
\hline Cristela Alonso & Female & 39 & Hispanic & 364,549 & 12 & 44,325 & $\begin{array}{c}\text { Episode } 82(\mathrm{~S} 2) \\
20 / 1 / 2017\end{array}$ \\
\hline Daniel Kaluuya & Male & 29 & Black & 404,488 & 13 & 45,859 & $\begin{array}{c}\text { Episode } 71(\mathrm{~S} 3) \\
16 / 01 / 2018\end{array}$ \\
\hline Elon Musk & Male & 46 & White & 167,691 & 4 & 13,905 & Episode 2 (S1) 9/09/2015 \\
\hline Michael Hayden & Male & 73 & White & 448,257 & 5 & 14,050 & $\begin{array}{c}\text { Episode } 109(\mathrm{~S} 2) \\
7 / 03 / 2017\end{array}$ \\
\hline Joseph Biden & Male & 75 & White & 625,797 & 7 & 18,495 & $\begin{array}{c}\text { Episode 55 } \\
(\mathrm{S} 2) 6 / 12 / 2016\end{array}$ \\
\hline $\begin{array}{c}\text { John } \\
\text { McWhorter }\end{array}$ & Male & 52 & Black & 412,383 & 7 & 31,120 & $\begin{array}{c}\text { Episode } 94(\mathrm{~S} 3) \\
27 / 02 / 2017\end{array}$ \\
\hline Riz Ahmed & Male & 35 & Asian & 543,923 & 13 & 39,420 & $\begin{array}{c}\text { Episode } 198(\text { Season } 1) \\
29 / 08 / 2016\end{array}$ \\
\hline Sheryl Crow & Female & 56 & White & 290,501 & 3 & 9,535 & $\begin{array}{c}\text { Episode } 132(\mathrm{~S} 2) \\
20 / 4 / 2017\end{array}$ \\
\hline $\begin{array}{c}\text { Sigourney } \\
\text { Weaver }\end{array}$ & Female & 68 & White & 454,829 & 5 & 17,870 & $\begin{array}{c}\text { Episode } 126(\mathrm{~S} 2) \\
5 / 04 / 2017\end{array}$ \\
\hline Susan Sarandon & Female & 71 & White & 676,788 & 5 & 11,560 & Episode $123(\mathrm{~S} 2)$ \\
\hline
\end{tabular}

Table 2. Controlled vocabulary for coding.

\section{Humour type}

Situational humour, narrative Frowning (to bring eyebrows joke, pun, irony, sarcasm, exaggeration, understatement, teasing, hyper-understanding, misunderstanding, parody, register humour, anecdote, absurd humour, insider humour, joint fantasy, stereotype humour, metahumour, self-mockery, selfglorification, gender humour, sexual humour, inter-textual humour.

\section{Face gestures} together)

Raised eyebrows (to lift one or both eyebrows) the corners of the mouth, with the front teeth exposed at times/accompanied by spontaneous sound)

Blank face (expressionless, neutral position of facial features)
Smile/laughter (to turn up

\section{Head movements}

Nod (downward rotation around axis $\mathrm{Y}^{*}$ )

Tilt (rotation around axis $\left.\mathrm{X}^{*}\right)$

Turn (single rotation around axis $\left.Z^{*}\right)$

Shake (repeated sweeps around axis $Z^{*}$ )

Upstroke (upward rotation around axis $\mathrm{Y}^{*}$ )

Protrusion (forward slide along axis $\mathrm{X}$ )*

Retraction (backward slide along axis $\mathrm{X})^{*}$

* See Fig. 3 for description of axis 
Table 3. Humour types found in sample.

\begin{tabular}{|c|c|}
\hline Humour type & Number of occurrences in sample \\
\hline anecdote & 33 \\
\hline irony & 17 \\
\hline parody & 16 \\
\hline self-mockery & 9 \\
\hline exaggeration & 7 \\
\hline insider humour & 7 \\
\hline sarcasm & 6 \\
\hline hyper-understanding & 5 \\
\hline stereotype humour & 5 \\
\hline teasing & 4 \\
\hline situational humour & 3 \\
\hline inter-textual humour & 2 \\
\hline joint fantasy & 2 \\
\hline self-glorification & 2 \\
\hline absurd humour & 1 \\
\hline meta-humour & 1 \\
\hline pun & 1 \\
\hline sexual humour & 1 \\
\hline understatement & 1 \\
\hline
\end{tabular}

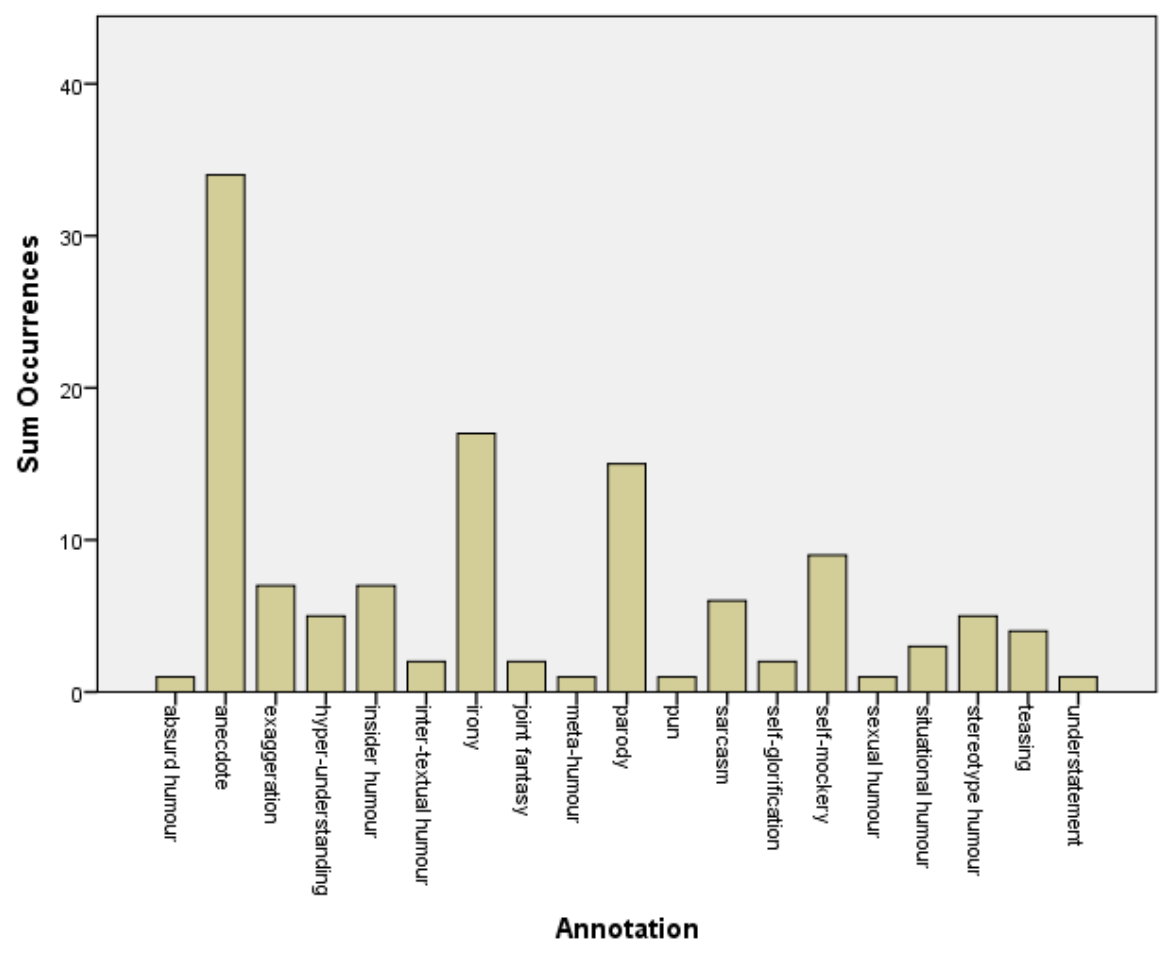

Figure 1. Humour types found in sample. 
Gestures in humorous utterances were annotated by the author going through the video frame by frame. During gesture coding the sound was off in order to avoid bias from cospeech (Flecha-García 2010; Debras \& Cienki 2012). Four coding rounds were conducted on each file. Table 4 and Fig. 2 summarise the gestures found in the sample and their number of occurrences.

Table 4. Gestures found in sample.

\begin{tabular}{|c|c|}
\hline Gesture & n \\
\hline nod & 91 \\
\hline tilt & 79 \\
\hline raised eyebrows & 65 \\
\hline turn & 53 \\
\hline shake & 47 \\
\hline smile & 41 \\
\hline upstroke & 35 \\
\hline frowning & 17 \\
\hline protrusion & 12 \\
\hline retraction & 2 \\
\hline blank face & 2 \\
\hline
\end{tabular}

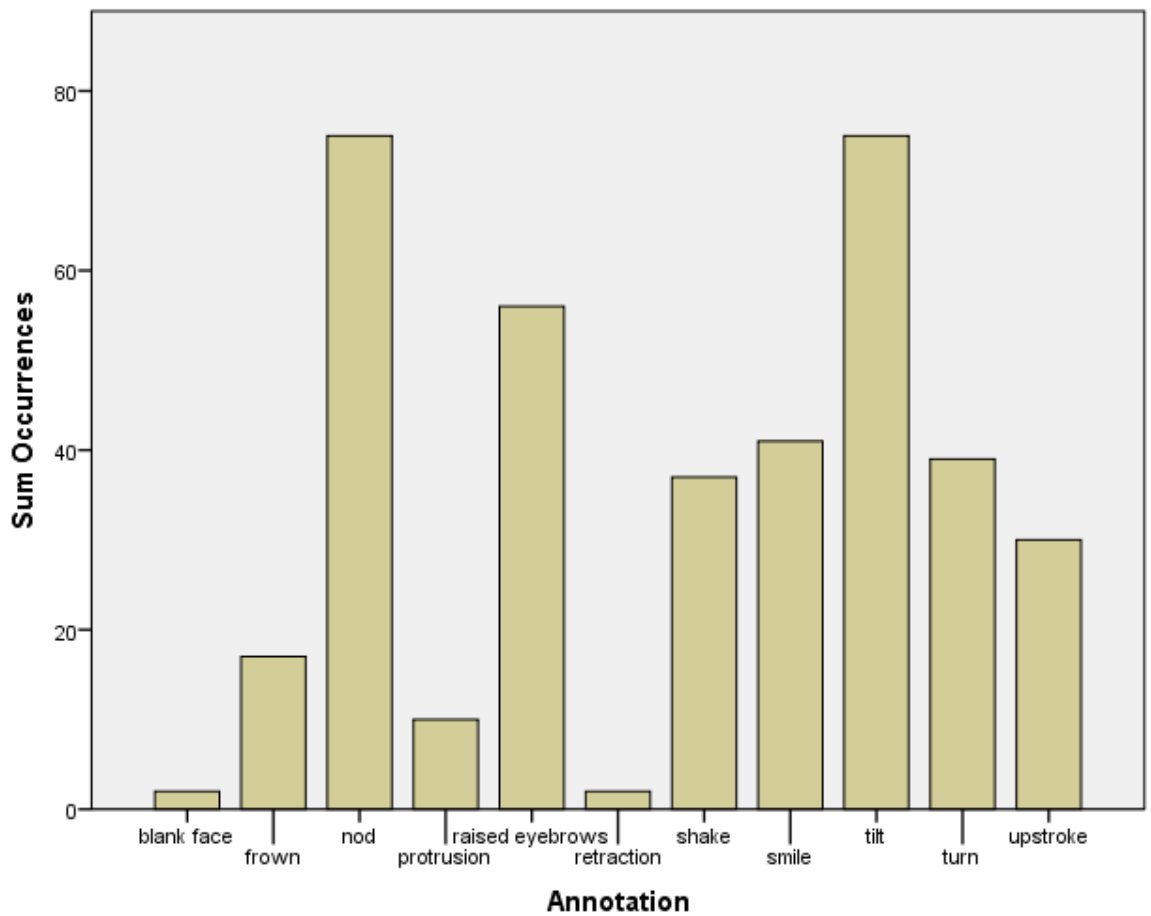

Figure 2. Gestures found in sample. 
Cross-reference data on the occurrence of each type of gestures with humour types is included in Table 5. No strong correlation emerges from this distribution, as the most frequent gestures mostly cluster around the humour types with the highest number of occurrences (in bold).

Table 5. Head and face gestures per type of humour.

\begin{tabular}{|c|c|c|c|c|c|c|}
\hline & nod & tilt & raised eyebrows & smile & turn & shake \\
\hline irony & $\mathbf{1 9}$ & $\mathbf{1 1}$ & $\mathbf{9}$ & $\mathbf{6}$ & $\mathbf{1 5}$ & 2 \\
\hline inter-textual & 2 & & & & 2 & \\
\hline self-mockery & 2 & 6 & 5 & 1 & & 5 \\
\hline teasing & 1 & 1 & 4 & 4 & & 1 \\
\hline hyper-understanding & 2 & 2 & 2 & 4 & 1 & 1 \\
\hline parody & 5 & $\mathbf{1 1}$ & $\mathbf{8}$ & $\mathbf{7}$ & $\mathbf{6}$ & $\mathbf{1 0}$ \\
\hline anecdote & $\mathbf{1 5}$ & $\mathbf{3 1}$ & $\mathbf{1 5}$ & $\mathbf{9}$ & $\mathbf{1 9}$ & $\mathbf{1 1}$ \\
\hline insider humour & $\mathbf{1 7}$ & 2 & 1 & 1 & 2 & 1 \\
\hline sarcasm & 3 & 5 & 2 & 1 & 2 & 3 \\
\hline exaggeration & 8 & 3 & 5 & 2 & 3 & $\mathbf{9}$ \\
\hline pun & 6 & & & & & \\
\hline joint fantasy & 3 & & 2 & 1 & & 1 \\
\hline stereotype humour & 3 & 4 & 7 & 2 & 2 & 2 \\
\hline self-glorification & & 1 & 2 & & & \\
\hline understatement & 1 & 1 & & & & 1 \\
\hline absurd humour & 2 & 1 & & 1 & & \\
\hline meta-humour & 1 & & 1 & & & \\
\hline situational humour & 1 & & 2 & 2 & 1 & \\
\hline
\end{tabular}

Gestures can perform the following functions: discursive, referential, and interactional (Ladewig 2014a). Of the types of gestures along the Kendon's continuum (McNeill 1992), the ones relevant for the current analysis are gesticulations, i.e.: co-speech gestures made unwittingly by the speaker, mostly with discursive and interactional value. Communicative head movements involve rotations around three axis, as shown in Fig. 3: axis Y, axis Z, axis X. In addition, two linear displacements are also common, along the $\mathrm{Y}$ and $\mathrm{X}$ axis respectively (Wagner et al. 2014).
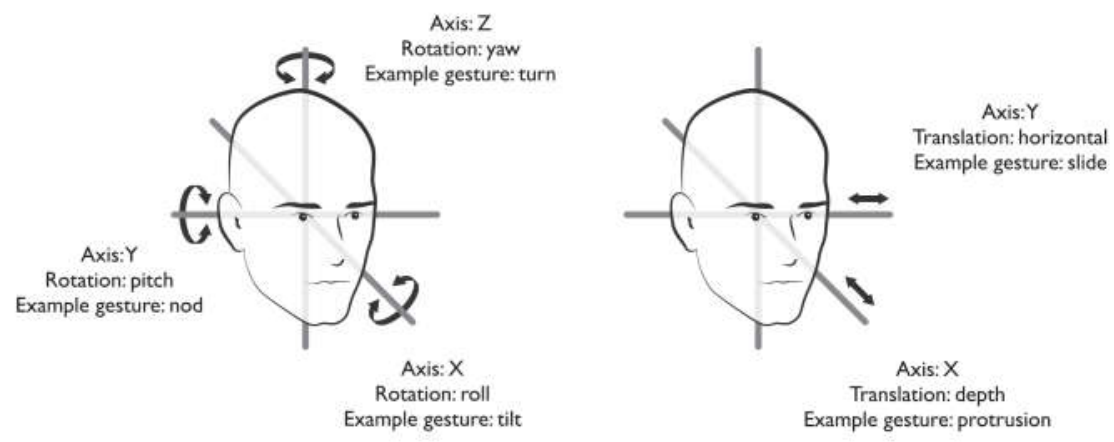

Figure 3. Head movements (Wagner, Malisz \& Kopp 2014: 212). 
The actual performance of these movements is varied, in terms of extent, angles, etc. Both head and face movements may overlap, and they may be produced repeatedly. For the current analysis, a minimalist approach has been taken, annotating only the type of gesture produced, regardless of the angle, extent, or number of repetitions. The reason to apply this minimalist approach has to do with the constraints imposed by the sample, where camera shots were not always taken from the same viewpoint or angle. I believe that this coarse-grained approach enables understanding of multimodal communication, pointing to possible patterns of interplay between gestures and speech.

\section{Facial gestures}

Face gestures, i.e. gestures performed with face muscles, such as smiling, frowning, squinting, raised eyebrows, etc., have been assigned various communicative functions in the literature (Poggi \& Pelachaud 1998): (1) affective display, with seven universal prototypical faces (Ekman \& Friesen 1971), showing happiness, sadness, fear, anger, disgust, and surprise (Ekman 1982), and embarrassment (Castelfranchi \& Poggi 1990); (2) syntactic function, when facial expressions punctuate questions, emphasis, intonational accents, pauses, etc. (Poggi \& Pelachaud 1998); (3) dialogic function, when face signals are produced in interaction to manage turn taking (Goodwin 1980); (4) referring function, when speakers use facial displays to refer to an emotion that they are not feeling at the moment of speaking (Ekman 1979); (5) attitude display, when face gestures express the speaker's attitude towards the interlocutor, e.g. to express anger through frowning, or agreement through a smile (Poggi \& Pelachaud 1998).

\subsection{Raised eyebrows}

\subsubsection{The function of raised eyebrows}

Facial displays can be used to express emotions or as conversational tools (Ekman 1979). Raised eyebrows are used as tools to gain the interlocutor's attention, either to express the will to take the turn in conversation or to signal the importance of a particular portion of speech (Guaitella et al. 2009; Kim et al. 2014). They can also serve to guide the coherent structure of discourse, and to underline certain bits of information (Flecha-García 2010). In addition, they strongly correlate with pitch accents (Guaitella et al. 2009; Flecha-García 2010). Tabacaru (2014) delved into the multimodality of humour, and provided an in-depth analysis of the relation between raised eyebrows and frowning with the humorous instances she identified in her corpus. She found that raised eyebrows are consistently associated to sarcasm, and concluded that they can serve as gestural triggers (Tabacaru \& Lemmens 2014), which cooccur with the "core humorous part of an utterance" (Tabacaru 2014: 217) to signal that such utterance has to be interpreted as humorous.

\subsubsection{Raised eyebrows in sample}

Raised eyebrows are the most frequent facial gesture found. Interestingly, no strong correlation appears between raised eyebrows and sarcasm, as opposed to the results obtained by Tabacaru (2014), although, arguably, the number of instances of sarcasm in the present sample (6) is too low to draw any significant conclusion.

Example (1) shows an instance of raised eyebrows in an anecdote. Sigourney Weaver is speaking about her recent trip to Cuba, and how she was so pleasantly surprised to see the classical education afforded to all artists. At one point, she is describing the Art School building, likening it to a womb, as if artists would emerge re-born from it after their artistic 
education period. Arguably, the audience laughs as a result of the unlikely description of the entrance to the building as having the form of a vagina.

(1) Sigourney Weaver: It's in an art school built on the golf course. They got rid of the golf course after the revolution and they built this womb-like... It's literally...You walk into a vagina-like opening...

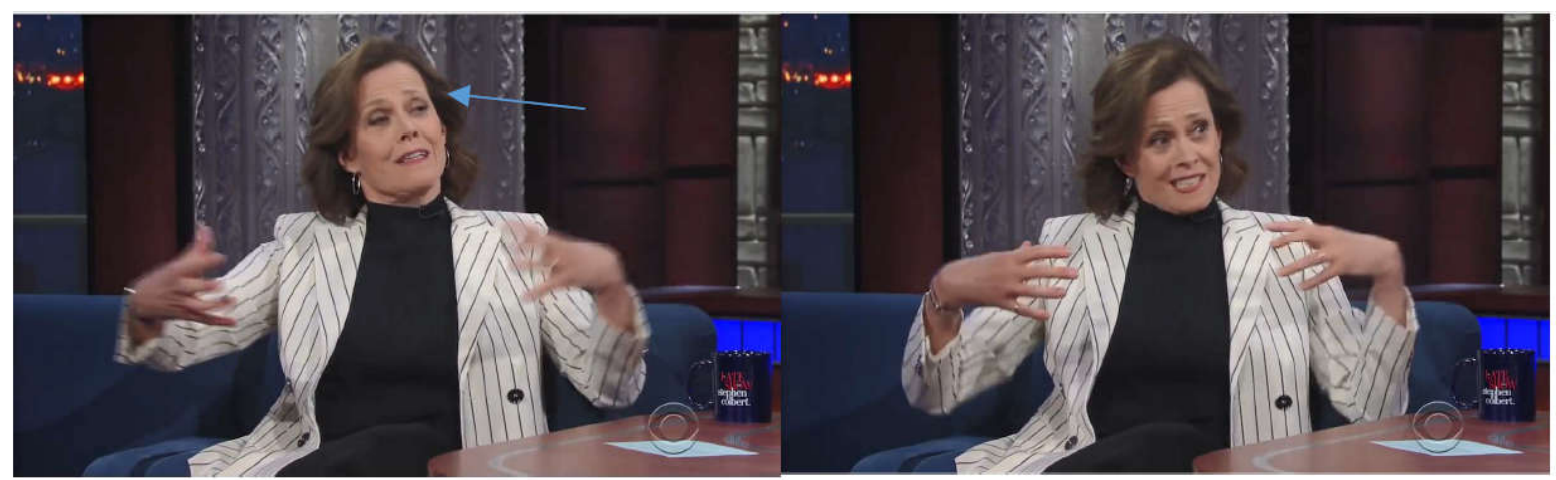

It's...

literally...

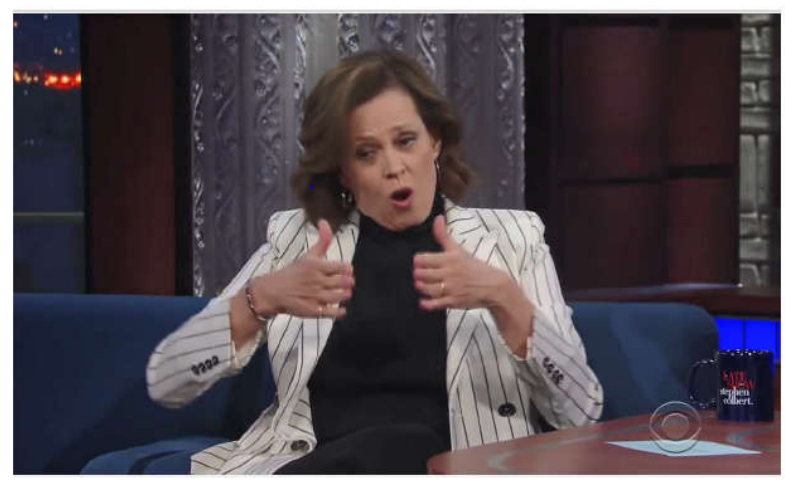

You walk into a...

Figure 4. Raised eyebrows in example (1).

Sigourney Weaver raises her eyebrows at the beginning of the sentence "It's literally". Her gesture could be interpreted as a way of signalling the non-conventional nature of what she is going to say next and draw attention to it. Raised eyebrows in this instance serve to underline that particular chunk of speech which, arguably, the speaker thinks deserves more attention. The utterance is accompanied by a variety of gestures, among which head tilts, nods, frowning, and smiles, in addition to representational hand gestures depicting the entrance to the building. The raised-eyebrows gesture does not co-occur with the core humorous element of the utterance, which is arguably the "vagina-like" simile, so it cannot be said to be a gestural trigger (Tabacaru \& Lemmens 2014). Accordingly, this particular instance of raised eyebrows cannot be clearly linked to the humorous nature of the utterance as such.

Example (2) presents an instance of irony. Sheryl Crow is discussing her latest album, which includes a song about collusion between Russia and a fictional American President, far earlier than suspicions arose about possible Russian interference in the 2016 American elections. 
(2) Sheryl Crow: I was sitting with my buddy, going, "Wow, what's the craziest thing you can imagine... like Russia, like Russia hacking. That'd be crazy. And like, uh...the President being involved with Russia. That'd be so fucked up!"

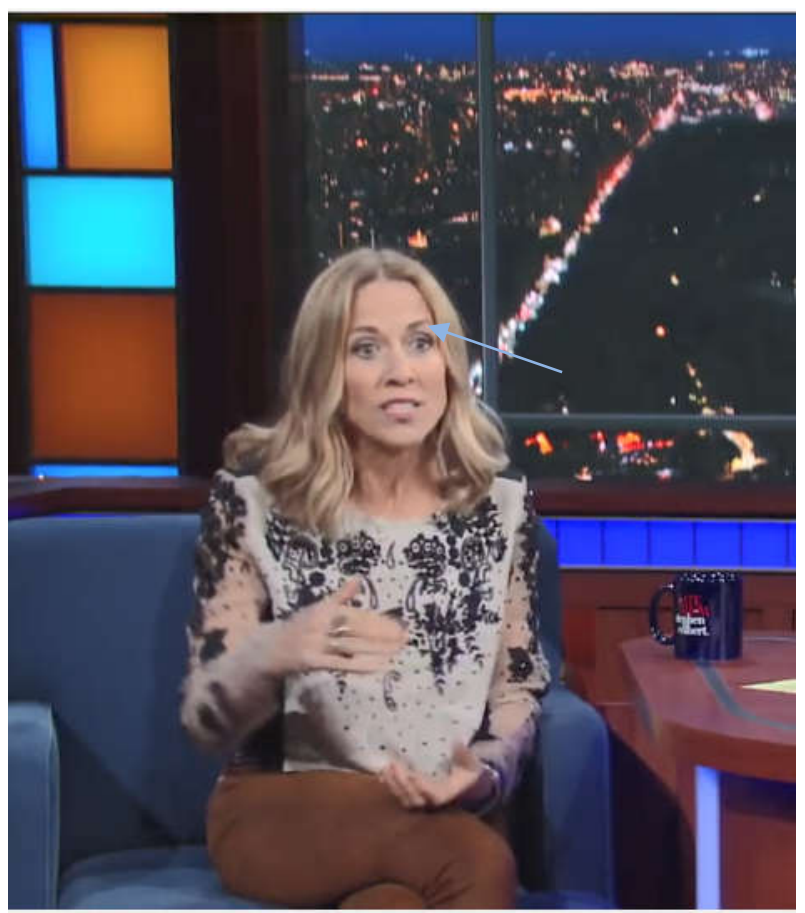

The President...

Figure 5. Raised eyebrows in example (2).

Sheryl Crow raises her eyebrows upon uttering "the President", so it can safely be claimed that she underlines the piece of information that she finds the most relevant, where the highest incongruity lies, as if conveying that the idea of having a President colluding with a foreign power is so serious that it is beyond imagination. In this case, "the President" is not only highlighted by the raised eyebrows, but also by protruding the head. In addition, the prosodic accent falls on the word "President". Hence, various multimodal cues, i.e., accent, raised eyebrows, and protrusion of the head, align to give clear prominence to that part of the sentence, where the core of the irony, in this particular example, is placed, so these multimodal cues serve as gestural triggers (Tabacaru 2014). Clearly, Sheryl Crow is underlining the implausibility of her idea at the time in order to highlight the opposition between the situation as they construed it then, in which no grounds to suspect anything of the like existed, and the current circumstances, in which the legitimacy of the President himself is questioned precisely because of a similar situation.

A further instance of raised eyebrows can be found in John McWhorter's interview. To the question of whether there is a word in English whose meaning has not changed through time, the lexicographer answers that the most frequently used and dullest words are the ones that change the least, and gives the preposition 'and' as an example.

(3) John McWhorter: For example, 'and'. I have nothing remotely interesting to say about 'and'. 


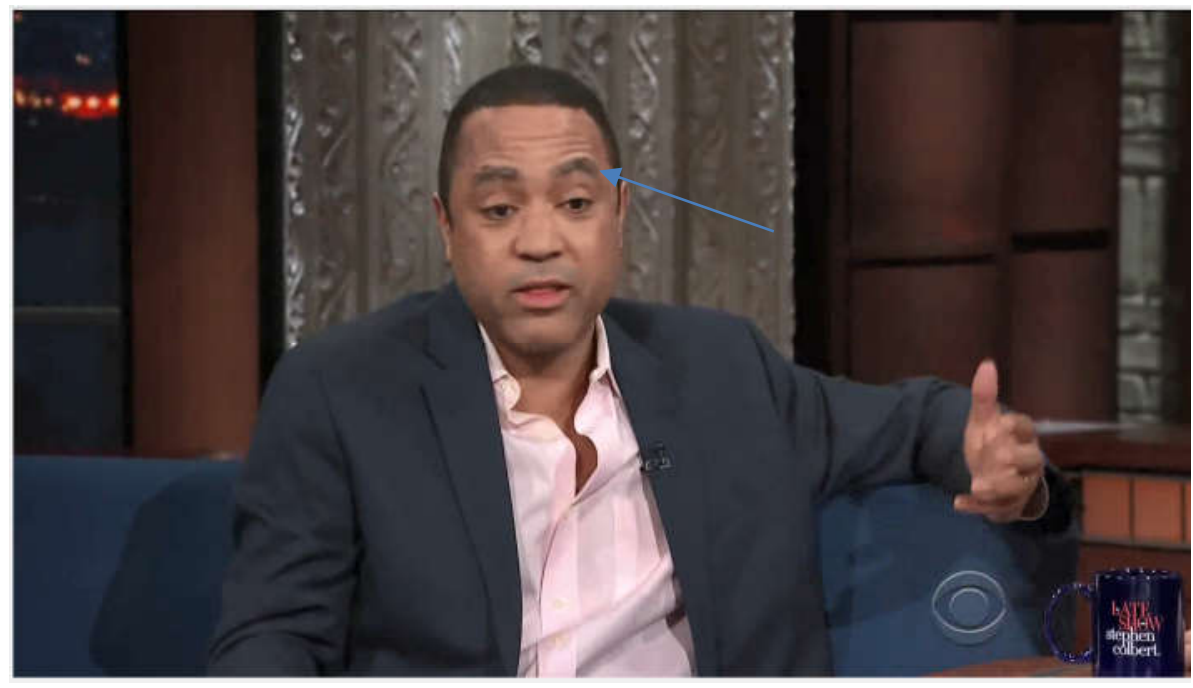

Figure 6. Raised eyebrows in example (3).

This is an interesting example, as the speaker keeps his eyebrows raised throughout the whole statement, but he raises them a bit higher upon uttering "and", "nothing", and "interesting", which, in this case, are the most meaningful words. Again, raised eyebrows are aligned with the most prominent words in terms of prosody, so these gestures serve to underline the most relevant bits of information provided.

A final example is extracted from General Michael Hayden's interview, in a token of hyper-understanding. Hyper-understanding refers to the ability of a speaker to reverse the intended meaning of an interlocutor's utterance by exploiting potential weaknesses in it (Veale et al. 2006; Brône 2008). General Hayden tricks the host into thinking that he is going to give away a juicy piece of information by asking a question usually put when people are going to say something important. However, he subsequently profiles just the literal meaning of the question, by answering it himself too, in order to stress that he is bound to keeping secrecy.

(4) General Hayden: Can you keep a secret?

Stephen Colbert: Turn off the cameras...I can keep a secret.

General Hayden: $\quad$ Me too.

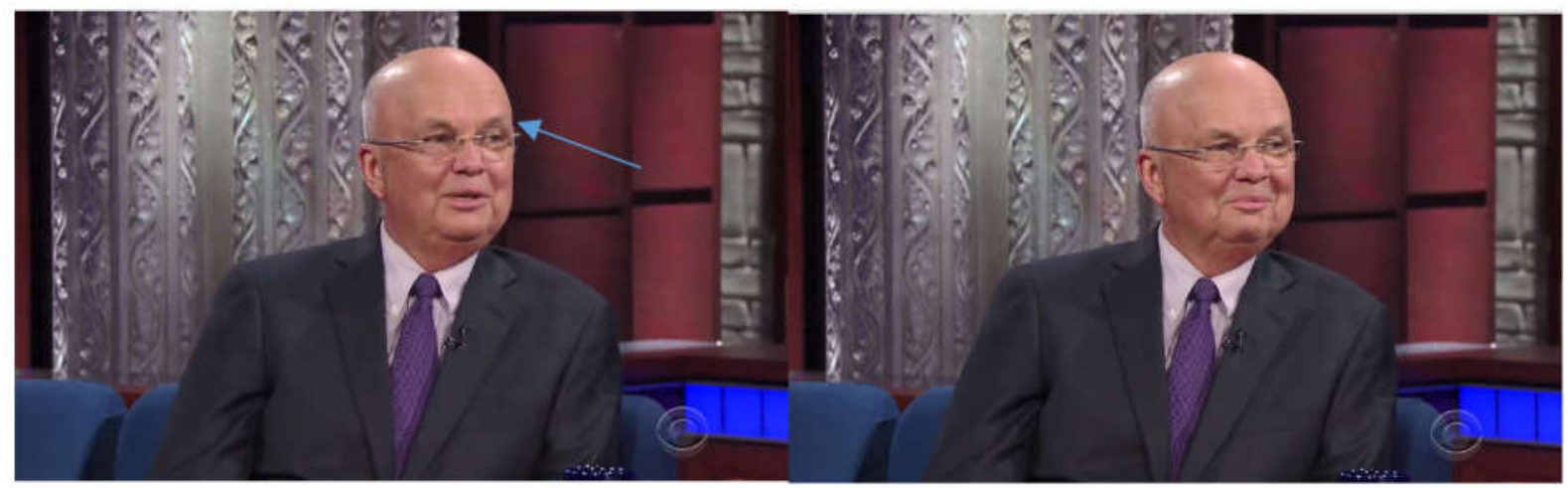

Me... ...too.

Figure 7. Raised eyebrows in example (4). 
General Hayden raises his eyebrows upon the pronunciation of "Me too". I posit that the raised eyebrows in this example serve to highlight the unexpected turn in the conversation, as under normal circumstances, speakers do not ask this question in order to answer it themselves. It can also be associated to the idea of surprise that is intended to cause in the hearer. Furthermore, by underlining the incongruity underlying his reply, General Hayden's humorous intent with this remark is reinforced.

The results of the analysis above are consistent with the claim that raised eyebrows can be used as underliners (Ekman 1979; Tabacaru 2014) to highlight parts of the speech that the speaker considers that deserve more attention. Raised eyebrows tend to align with prosody to make salient elements in the utterance clearer to the interlocutor. They would therefore serve to direct the hearer's attention to the most meaningful parts of the speech to favour a correct interpretation, as intended by the speaker.

\subsection{Smile and laughter}

Laughter and humour do not consistently go hand-in-hand, as the former can occur without the latter and vice-versa (Morreall 1983). Norrick (1993) argued that laughter is the natural response to humour by the hearer, and that its absence would point to failed humour. Provine (2000) and Hay (2001), nevertheless, dissociated humour and laughter as a necessary and inevitable response. Having said that, laughter remains a valid indicator of humour in the literature, given how frequently it co-occurs (Holt \& Glenn 2013; Gironzetti 2017).

With regards to smiles, only recently has research taken an interest in exploring from a multimodal perspective how smiling and humour are related (Attardo et al. 2013; Ikeda \& Bysouth 2013; Gironzetti \& Menjo 2014; Gironzetti et al. 2015). Ikeda and Bysouth (2013) associated smile and laughter, along with other multimodal cues, e.g. gaze, as features that, combined, may have communicative value to signal, for example, appreciation. Attardo et al. (2013), in turn, found in their study that smile and laughter were the only multimodal cues frequently co-occurring with humour. They concluded, though, that neither smiling nor laughter can be taken as markers of humour, as they are not consistently associated with it. For them, laughter and smile are not linked to the hearer's reaction to humour, but to the way speakers signal their humorous intention, as part of a negotiation between interlocutors to determine when a given turn is to be comprehended as humorous (Attardo 1994; Eisterhold, Attardo, and Boxer 2006). This hypothesis was borne out by other studies, showing that humorous turns were consistently associated with higher-intensity smiles and smiling synchrony among interlocutors (Gironzetti \& Menjo 2014; Gironzetti et al. 2015).

Smile annotations in the sample include some instances of laughter, as the current analysis does not aim at disentangling the nature of both phenomena, but rather at looking into their association with humour and their possible function to frame humorous instances (Attardo et al. 2013). Smiling amounts only to $10.59 \%$ of the gestures co-occurring with humour annotated in the sample. That relative low frequency, though, may be due to the nature of the gestures themselves, as raised eyebrows or head movements tend to be shorter and repeated, whereas smiles can be maintained over a longer segment of speech, and therefore be annotated just once, despite covering longer stretches of utterances. A better measure of the cooccurrence of smiles and humour is to look into the percentage of humorous utterances in the sample in which speakers smile. Smile has been annotated in 41 out of 109 humorous utterances, which means that it is present in the production of $37.61 \%$ of the humorous instances identified. This frequency reveals that smile or laughter are by no means necessary to frame a given utterance as humorous nor to signal the humorous intent of the speaker. Perhaps, it could be argued that the context of the sample is prone to humour, given the genre 
of the programme and the interviews themselves. That might be a reason why smiling may not be essential, then, to frame any turn as humorous, as this is taken for granted in such a setting.

Example (5) is taken from Cristela Alonzo's interview. She is discussing with the host differences in how they were taught certain aspects of religion as children.

(5) Cristela Alonzo: You're gonna have a crown in Heaven?

Stephen Colbert: $\quad$ You get to Heaven, you get a crown. That's what I was told.

Cristela Alonzo: $\quad$ My mum would say: "Mija, in Heaven, you're gonna get electricity, running water..."

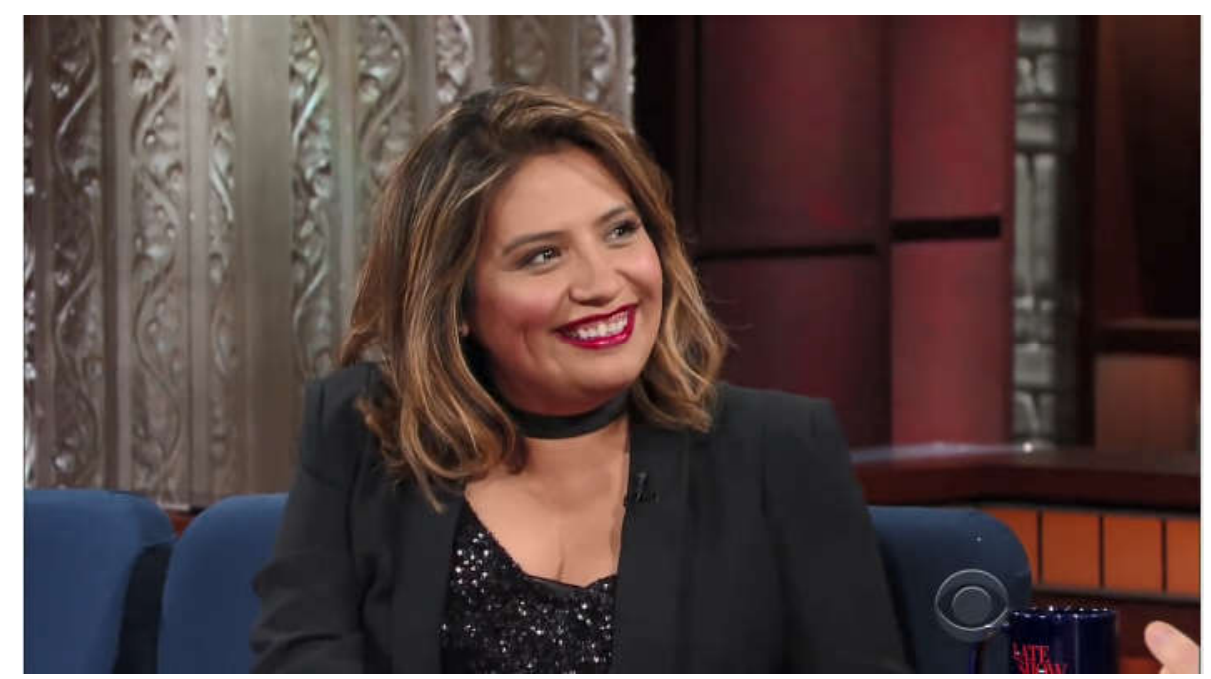

Figure 8. Smile in example (5).

She smiles at the end of the humorous utterance, corresponding to her last statement in the previous dialogue. In my view, smiling in this case is an indication of the humorous nature of Cristela Alonzo's words, and of her intent for the remark to be taken as such, despite pointing to a difficult childhood as the daughter of an immigrant Mexican mother with very few financial means.

Another example of smile can be found in the same interview, but this time co-occurring with frowning, which, as I see it, assigns a different value to the smile. Again, Cristela Alonzo is referring to her childhood to explain how she became passionate about comedy to the point of wanting to become a comedian herself. She stated that she watched many comedy shows on $\mathrm{TV}$, as she spent a lot of time alone in her house and TV was her main companion.

(6) Stephen Colbert: How did you get to comedy from there? Were there clubs in your town? How did you...?

Cristela Alonzo: No clubs whatsoever. I loved TV. I was a latchkey kid...

Cristela Alonzo: [on inaudible reaction by someone in the audience]: Ok [smile and frowning]. Ooh, times were tough. 

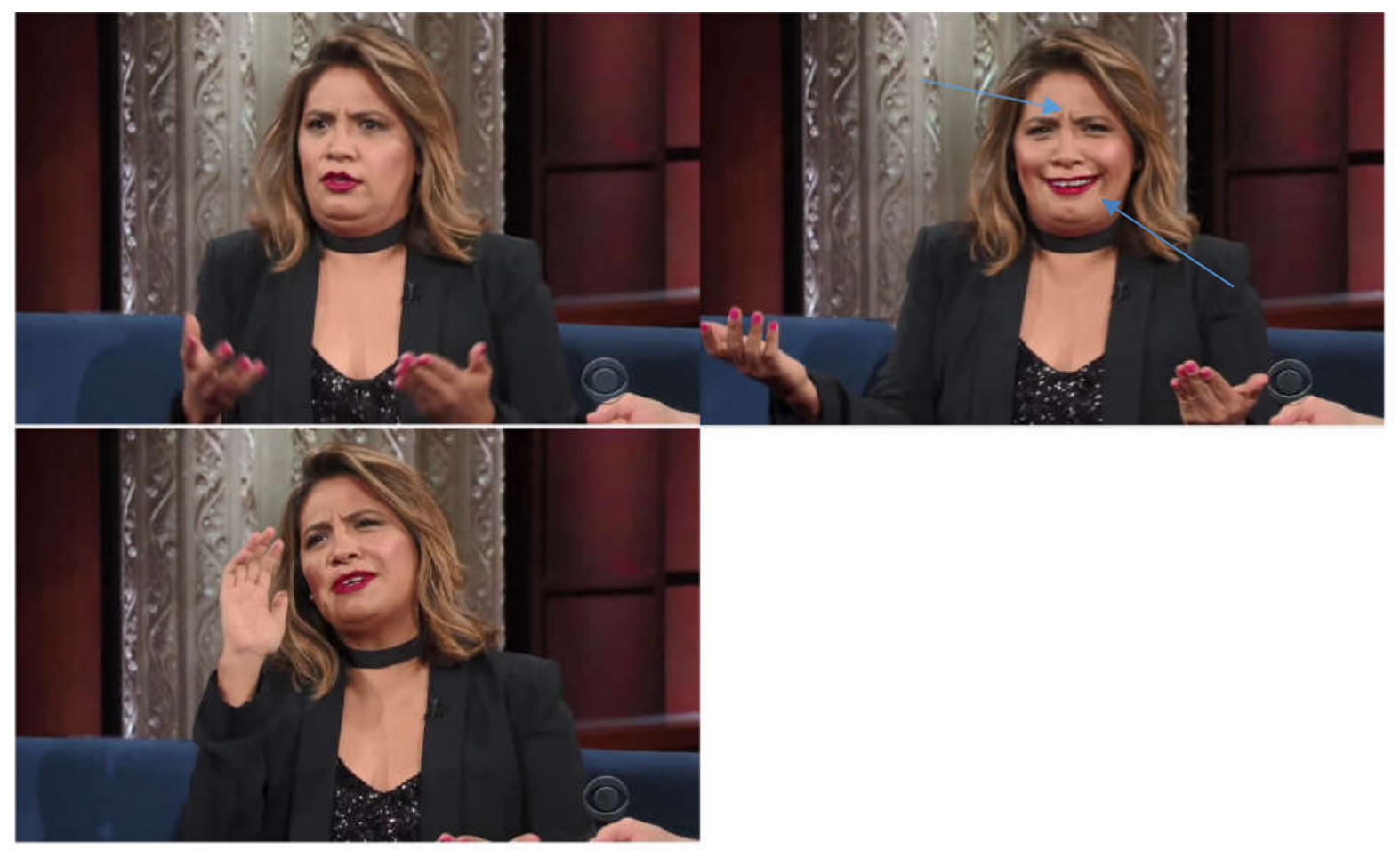

Ooh! Times were tough!

Figure 9. Smile and frowning, in example (6).

In this case, Cristela Alonzo's smile, which includes a short bout of laughter, does not cooccur with speech but substitute for it. After expressing her astonishment at the reaction by a member of the audience with the first 'Ok', she clearly conveys her disapproval through frowning, which has traditionally been taken as a sign of disagreement (Tabacaru 2014). Also, the position of the hands seem to be signalling disbelief or lack of understanding. Her smile in this case may be taken as an attempt to attenuate her rejection of the audience's reaction so as not to come across as outright confrontational, which would be out of place, given the casual context of the programme.

In addition, smiling could be a way of trying to conceal her negative emotions and to save face in order to keep the light and humorous tone expected at the interview, an attitude which is further reinforced by her response, after which she seems to dismiss the whole episode with a shrug, before turning to the host and resume her speech where she had left it before this interruption, by repeating "I was a latchkey kid". Beyond illustrating different ways in which smiling can be used, other than to express appreciation, encourage cooperation or signal humorous intent, I find this particular example to be a showpiece of how different multimodal channels interplay to convey much more than what is simply said.

In example (7) British actor Daniel Kaluuya is describing his experience at the Golden Globes, as a newcomer in a world of glamour and big film stars. He is specifically telling how he met Denzel Washington, and how overwhelming the whole experience was for him.

(7) Daniel Kaluuya: And Denzel spoke to me, and I'm like, he was like...I was like: I can't believe he knows who I am, I can't believe he knows who I am. And then...[mimicking Denzel's words to his wife] "He can't believe I know who he is". 


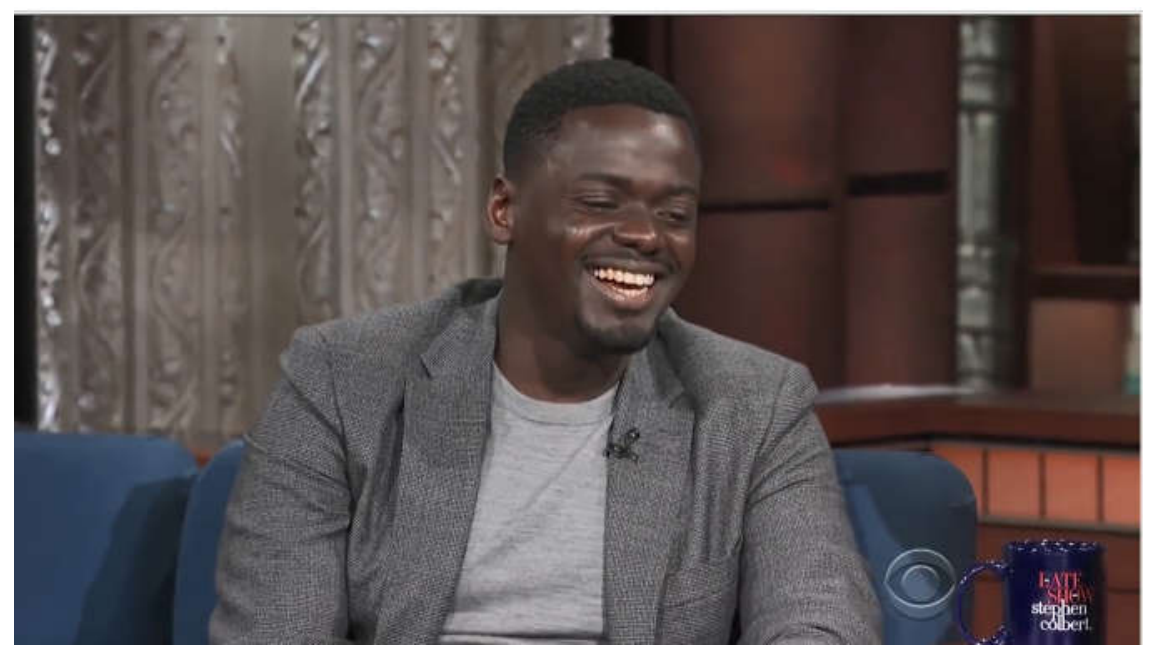

Figure 10. Smile in example (7).

In my view, this smile, which is produced right after the remark reported above, is not used to frame the turn as humorous. I consider Daniel Kaluuya's smile to be a reflection of his own positive feelings of bewilderment and overwhelm at such a dream come true for him. It is, therefore, an inward-looking smile, which is highlighted by the fact that the smile is not directed at the hearer, and no eye-contact is made by Daniel Kaluuya, so no agreement is sought on the part of the interlocutor in this particular utterance.

Finally, example (8) illustrates an instance of smiling and irony, from Vice President Biden's interview. It conveys Joseph Biden's answer to the question of what he felt on the 2016 election night, in which fellow democrat Hillary Clinton lost to Donald Trump.

(8) Vice President Biden: Well, I've been in the closet since then. I haven't come out...No.

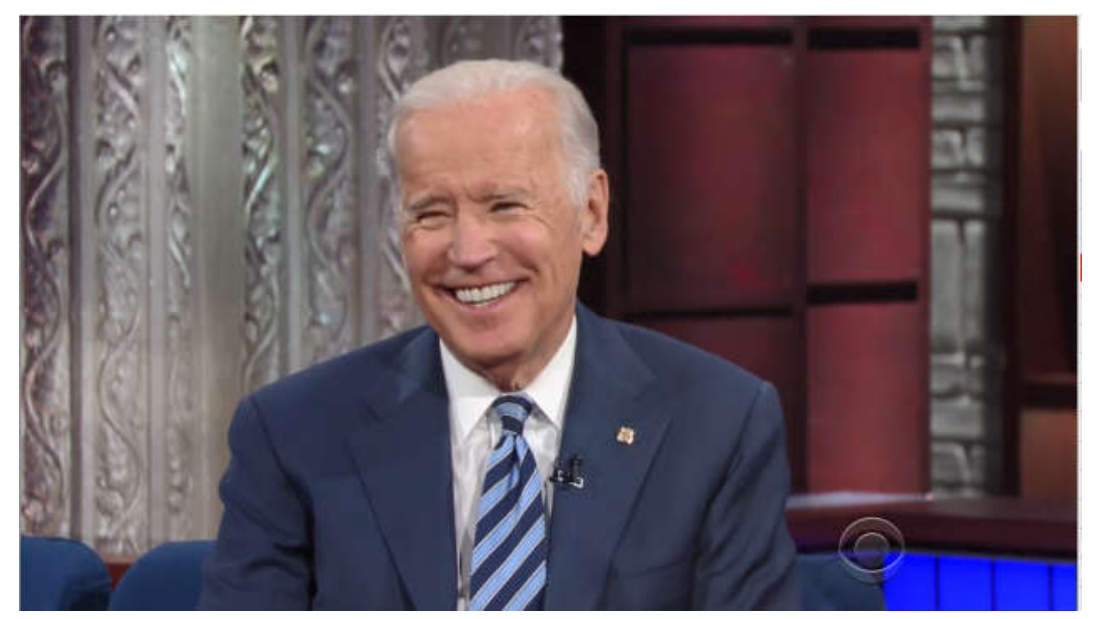

Figure 11. Smile in example (8).

Vice President Biden smiles right after pronouncing "No", which, in turn, negates the meaning of the preceding utterance, intended as ironical. In this case, I see the smile as clearly pointing to the humorous ironical nature of his remark, reinforced by the verbal negation of what he had just stated, as if to dispel any possible doubt about it.

As seen in the previous examples, smiles are not always necessarily associated to the humorous nature of an utterance. Even when they co-occur with humour, they do not always clearly signal a humorous intent on the part of the speaker. Smiles can also be just an 
expression of attitude or affective display, not necessarily tied to an intended communicative value by the speaker (cf. introduction in Section 3 ).

\section{Head movements}

Head posture changes constantly during speech (Maynard 1987). Head movements can have semantic, discourse, and communicative functions. Head shifts can regulate interaction, yielding or asking for turn (Hadar et al. 1984), or requesting backchanneling (Maynard 1987; McClave 2000; Altorfer et al. 2000). In addition, head movements can have deictic functions and locate referents in abstract space (McNeill 1992). Furthermore, switches in narrator while speaking, i.e. when the speaker refers someone else's words, can also be indicated by head movements (McClave 2000). Head movements can also be elicited to signal the humorous nature of what is being said (Lee \& Marsella 2010) or to give prominence to the elements of the utterance which carry the humorous meaning (Tabacaru 2014).

\subsection{Head tilts}

Head tilts and head nods are the most frequent gestures found in humorous utterances within the sample. Head tilts have been linked to disbelief, lack of understanding (Heylen 2008), interjections expressing denial, word searching (Lee \& Marsella 2006), and in segments or speech with weak boundaries, such as unfinished utterances or stretches in which speakers pause to think (El Kaliouby \& Robinson 2004; Ishi et al. 2014). Head tilts loosely align with prosody (Cvejic et al. 2010), although they do not synchronise with certain parts of utterances as strongly as nods or shakes (Ishi et al. 2014). In addition, Tabacaru (2014) claims that head tilts also serve as gestural triggers, underlining those parts in the utterance which are more significant to enable the humorous interpretation.

Example (9) has been extracted from General Hayden's interview. Stephen Colbert had brought about the subject of President Trump accusing President Obama of having wiretapped Trump Tower for campaign surveillance purposes. Former CIA director General Hayden explains that obtaining a court order for wiretapping is extremely difficult, and that they are only issued when probable cause of serious criminal activity is proved. The subsequent exchange follows:

(9) Stephen Colbert: [after mentioning that President Trump had called for an investigation on the issue] Can a President just find out by himself that this happened?

General Hayden: Yeah. That's why I wondered what happened on Saturday morning. He seemed... He seemed to have forgotten that he was the President of the United States.

General Hayden tilts his head upon pronouncing the first "seemed", and keeps it slightly tilted throughout the utterance, except for a further prominent tilt upon saying "forgotten", which is additionally punctuated by a nod. The onset of both tilts are clearly aligned with accented words: "seemed", and "forgotten".

It could be argued that the first tilt is associated to the unfinished utterance, although there does not seem to be a pause for thinking or retrieving the word. Instead, it seems to me that General Hayden is marking the beginning of a humorous sarcastic turn, as if requiring closer attention by the hearer. As said before, the second tilt falls upon "forgotten". Both "seemed" and "forgotten" are the most relevant elements in the utterance to facilitate its sarcastic interpretation, given the implausibility of anyone forgetting that they are the president of the 
US. Hence, in this case, tilts act as gestural triggers (Tabacaru \& Lemmens 2014). They also play a part in information structure, highlighting the most relevant pieces of new information.

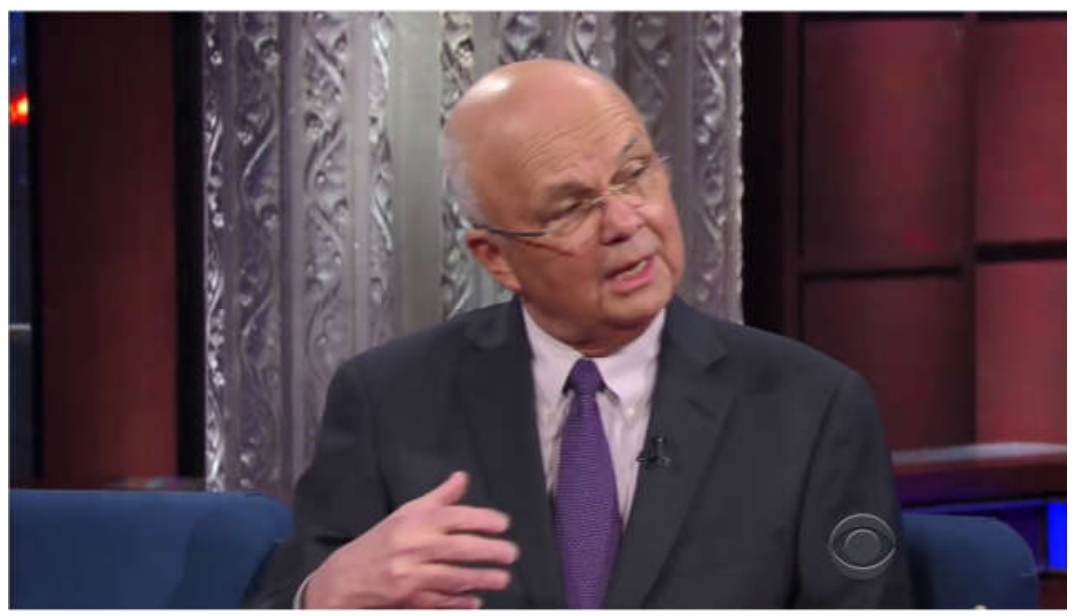

Figure 12. Tilt in example (9).

In example (10), however, head tilts do not seem to have the same function. In this case, Riz Ahmed is referring to how he switches to the required accent for the character he has to play in a given series, film, etc., the moment he sets foot in the place where that is going to be filmed, and keeps the character's accent even when he is not shooting. He explains that this leads to embarrassing situations in which, once the shooting is finished, when he goes to thank the team in his native British accent, people react badly as they feel betrayed.

(10) Riz Ahmed: They can feel quite betrayed, really. Because we wrap the whole shoot and I go to people: "Thanks a lot, mate. Nice one; I really appreciate it". [Reporting the team's reaction] "I don't even know you, you know?"

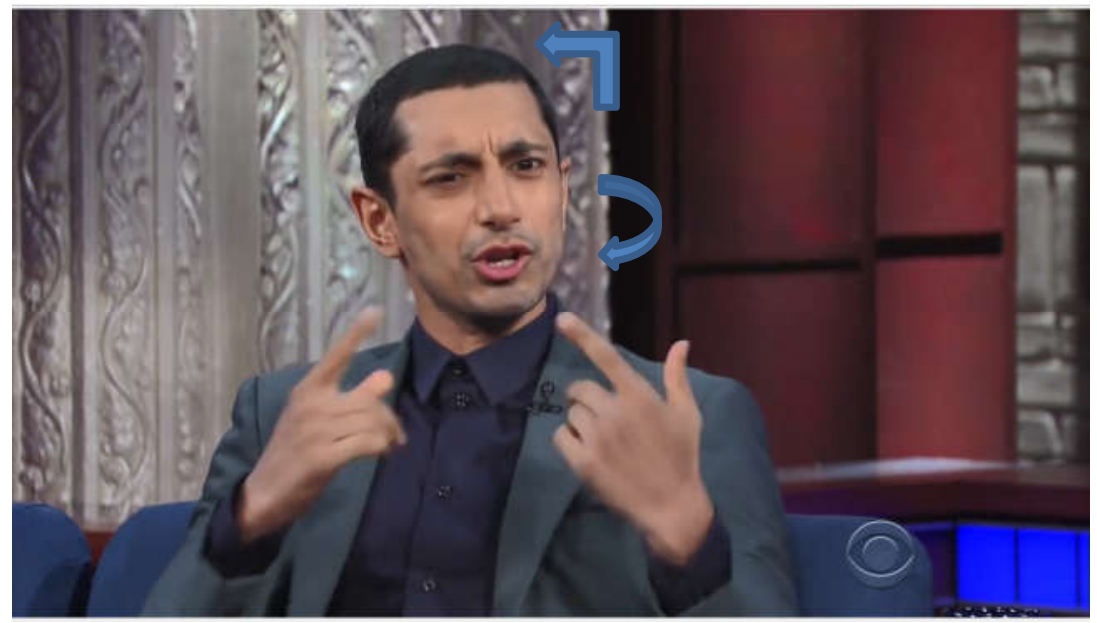

Figure 13. Tilt in example (10).

In this instance, there is a short tilt that falls upon the first "know", while he is reporting the reaction he gets from his team when they realise he talks differently from what they are used to. According to the literature survey reported above on the functions of tilts, this example could be associated to the expression of disbelief, and, in my view, it also has a clear use in terms of information structure, aligning with prosody to underline the most prominent word in that utterance. On another note, it is interesting to notice that Riz Ahmed does not express the 
transition to indirect speech verbally. Instead, he turns his head and gaze to a different space where he places the referent, i.e. the team he has worked with, in a distinct location to identify them, thus marking a change in narrator and in viewpoint (McClave 2000; Parrill 2012).

Example (11), from Alison Janney's interview, shows an example in which a tilt is combined with a head shake. She is explaining how she became interested in acting while in college, especially after realising she could not major in Psychology, as she was unable to conduct rat experiments in the lab.

(11) Alison Janney: I tried to major in Psychology and I had to deal with the rats, and I was like... I cannot do with the rat-lab part of Psych... Whatever, I don't know.

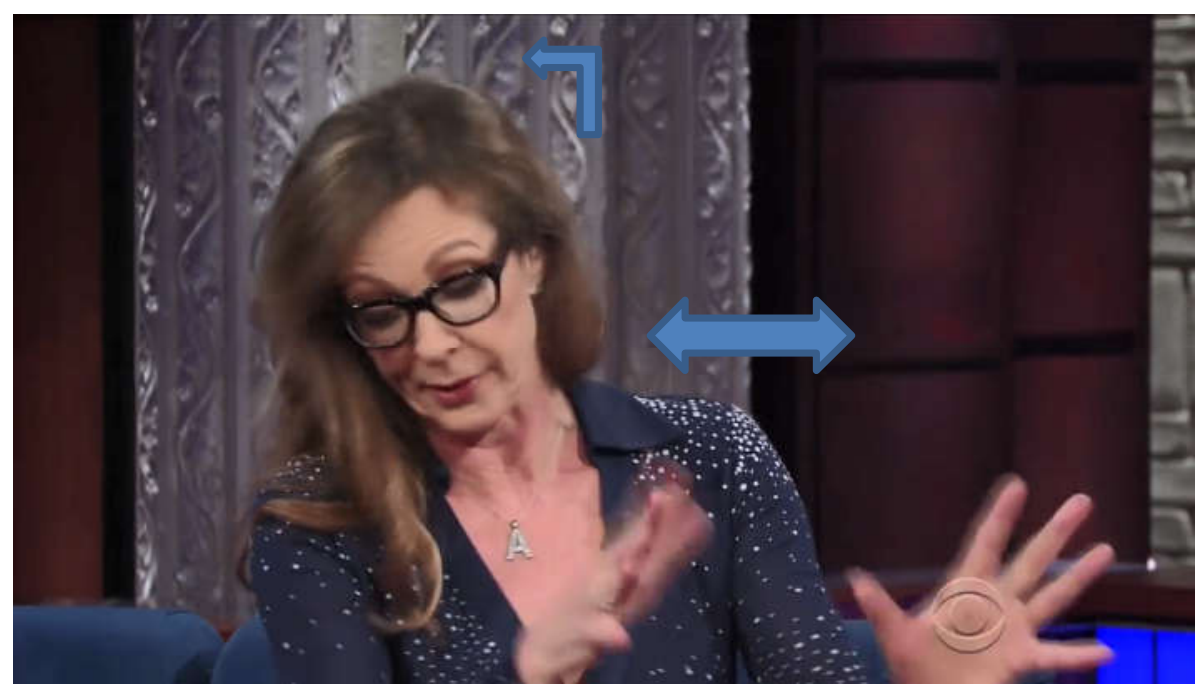

Figure 14. Tilt and shake in example (11).

Upon uttering "whatever", she tilts her head to the right, while also performing a shake. The tilt could be associated to the unfinished utterance, i.e., weak boundaries (Ishi et al. 2013). It also reinforces the expression of rejection and denial, clearly shown by the head shake and the position of the hands, as if pushing away the idea of having to work with rats in the lab. In any case, no clear connection seems to exist between the tilt and the humorous effect of the utterance, nor to the profiling of the rat experiments as part of how she explains her decision to study theatre at college.

An interesting instance from the same interview occurs in a later statement, in which she is telling that she was cast by Paul Newman to act in a university play he himself directed. When asked why she thinks she was chosen by Paul Newman to play the leading role, she explains that, in the casting, she came up with a monologue on fast driving, as she knew Paul Newman was very fond of cars. She hints to the possibility that her canning and seducing pretence to be a car-fan woman is what enticed Paul Newman into giving her the role.

(12) Alison Janney: And it probably had nothing, no reason, to do why I got the part. But I like to think that I... You know... I catfished him into... cast me. 


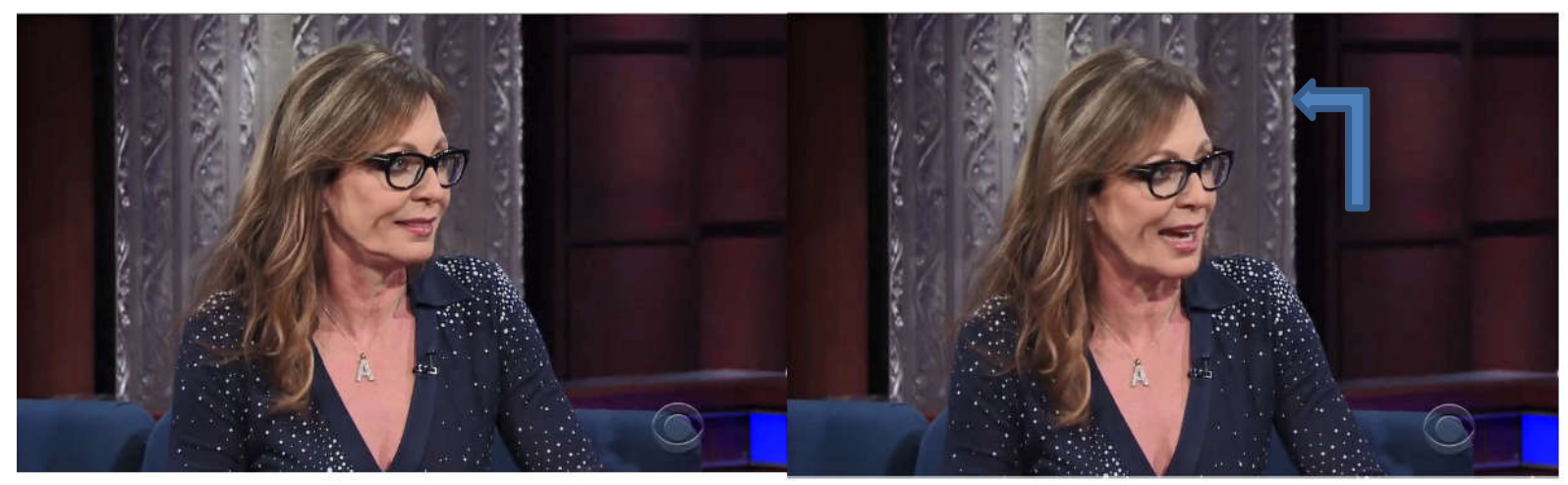

...into...

...cast...

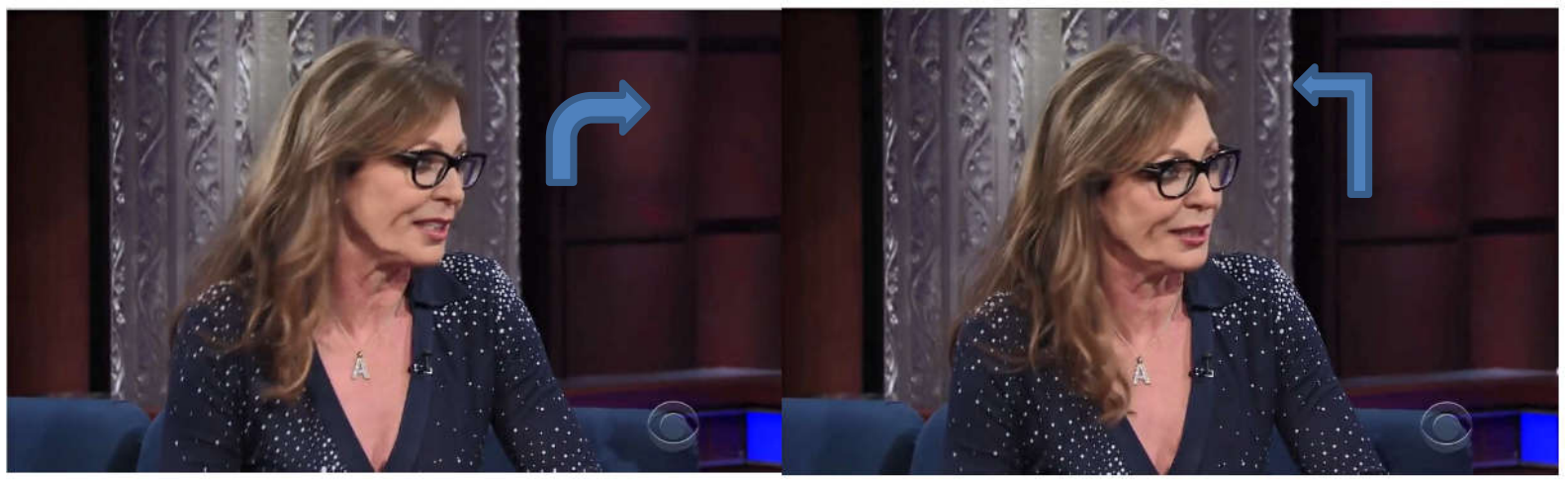

...me.

Figure 15. Head tilts in example (12).

The utterance identified as humorous corresponds to the latest part of this statement, i.e. "I catfished him into cast me". This utterance is punctuated by repeated head tilts. At first, short tilts accompany "I catfished him into...", whereas the last part, "...cast me", is framed by slightly more sweeping head tilts. It gives the impression that she is a bit unsure about what she is going to say at the beginning, as the seduction innuendo is clear, but then decides to go for it, stressing the humorous nature of the remark through her head motion of repeated tilts. The beginning of each head tilt cycle in this instance is clearly aligned with the accented part of the corresponding segment of speech, i.e., "I CATfished him into...CAST me". The nonserious nature of the utterance would be further reinforced by a smile at the end.

As shown in the previous examples, head tilts can be recruited for different functions, which appear to be the same in humorous as in non-humorous communication.

\subsection{Head nods}

Nods are typically associated with the semantic expression of agreement or acceptance (Poggi et al. 2010), but they can have different functions (Wagner et al. 2014), such as confirmation, approval, appreciation, emphasis, etc. (Poggi et al. 2010). They can also be used for turn taking or giving (Ishi et al. 2014) and strongly correlate with prosody (Swerts \& Krahmer 2010). Nods produced by speakers can function as backchannel requests, to which listeners have been found to be extremely sensitive (McClave 2000).

Example (13) illustrates an instance of a single nod in an utterance identified as belonging to hyper-understanding (Veale et al. 2006; Brône 2008). Stephen Colbert welcomes lexicographer John McWhorter and tells him that he listens to his podcast all the time, to 
which McWhorter replies "Keep listening". Arguably, humour arises from the unexpected nature of the remark, as what would be typically expected is a simple "thanks". By profiling the action of listening to McWhorter's podcast, instead of taking the remark just as a polite onset of the interview, the lexicographer reverses the host's statement to a certain extent, in order to exploit it for his own benefit.

(13) Stephen Colbert: Thanks for being here. I listen to your podcast all of the time... John McWhorter: Keep listening.

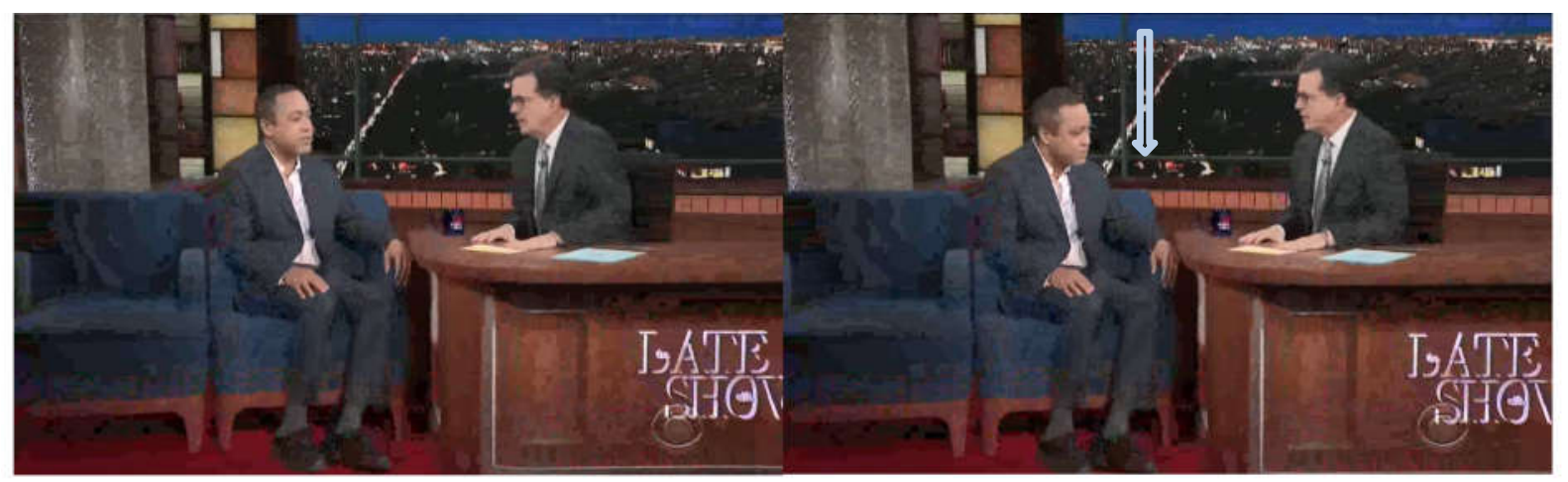

Figure 16. Nod in example (13).

John McWhorter produces a single nod, starting upon the pronunciation of "keep", which is also the most prominent word in the utterance, and ending in the baseline position at the end of the word "listening", so both the head movement and prosody strongly correlate. The nod in this example can signal appreciation or approval. Having said that, given that the nod movement is exaggerated, I believe that in this particular instance it is also used to place emphasis on the utterance, as a way of highlighting a non-conventional remark.

A different function can be interpreted in example (14), where several nods are performed. Vice President Biden replies to the question of what he expects from the Trump administration:

(14) Vice President Biden: Now, you're all gonna laugh when I say this [burst of laughter in the audience]. But the honest-to-God truth is, I don't know. But I'm being deadly honest to you. I don't think the President himself knows for certain.
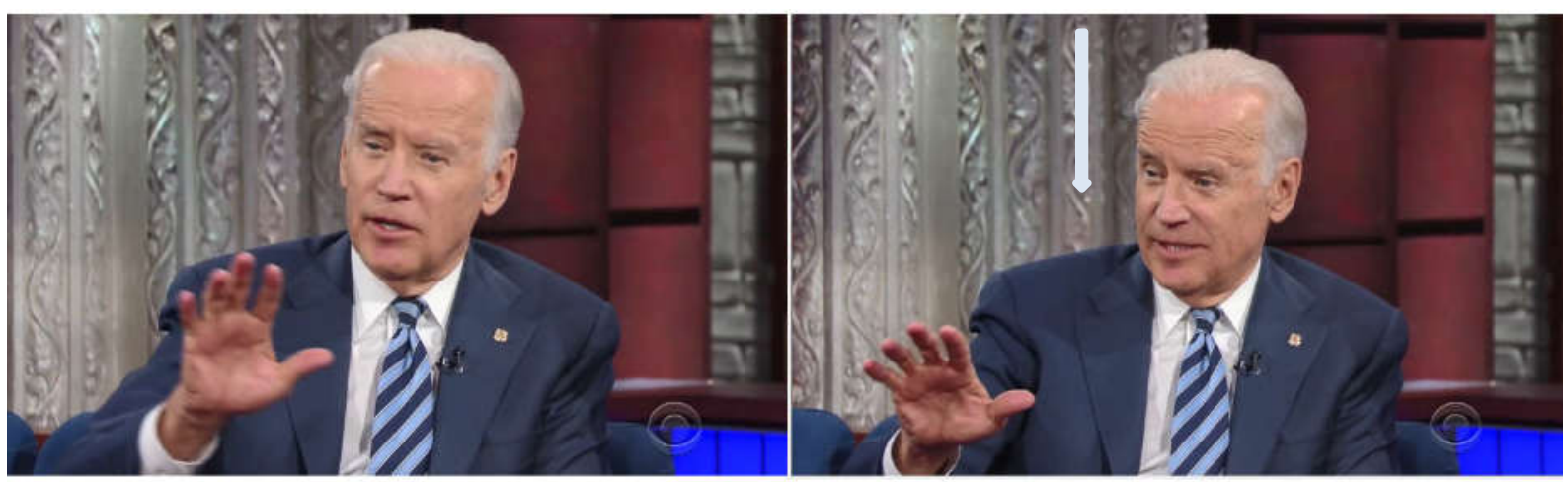

You're all gonna... ... laugh when I say this.

Figure 17. Nod in example (14). 
Two utterances were identified as humorous here: "You're all gonna laugh when I say this", as an example of meta-humour, and "I don't think the President himself knows for certain", as an instance of insider humour. The nod onset co-occurs with "laugh", which is the accented word in the utterance, and the head keeps down in this single nod until the end of the utterance. In my view, this nod is a backchannel request. It serves to engage the audience and to make sure the speaker has their full attention.

A further example of a nod to request backchanneling from listeners is found in the subsequent humorous remark. In this case, it correlates with the word "certain", at the end of the statement. To me, this nod is again intended to capture the hearers' acknowledgement of what is being said to make sure that they fully grasp its meaning. A different nod is produced in this very same utterance, coinciding with the word "President", which happens to be the most prominent word in that stretch of speech. This particular nod could serve to underline the term "President", as the most relevant word introducing new information, in which the agent switches from Joseph Biden to the President.

An illustration of a nod signalling confirmation and agreement can be found in example (15). Given the Pakistani background of actor Riz Ahmed, Stephen Colbert has asked him if he has experienced difficulties travelling to the US due to his physical appearance. Riz Ahmed replies that he frequently gets "randomly" selected for searches at security control, to which the subsequent exchange follows:

(15) Stephen Colbert: Riz Ahmed: Stephen Colbert: Riz Ahmed:
A secondary search?

Well, it's a random search, really.

Ok, I thought maybe it was a slightly deeper search.

Well, now I get searched by fans, so they can be really thorough, actually. Yeah.

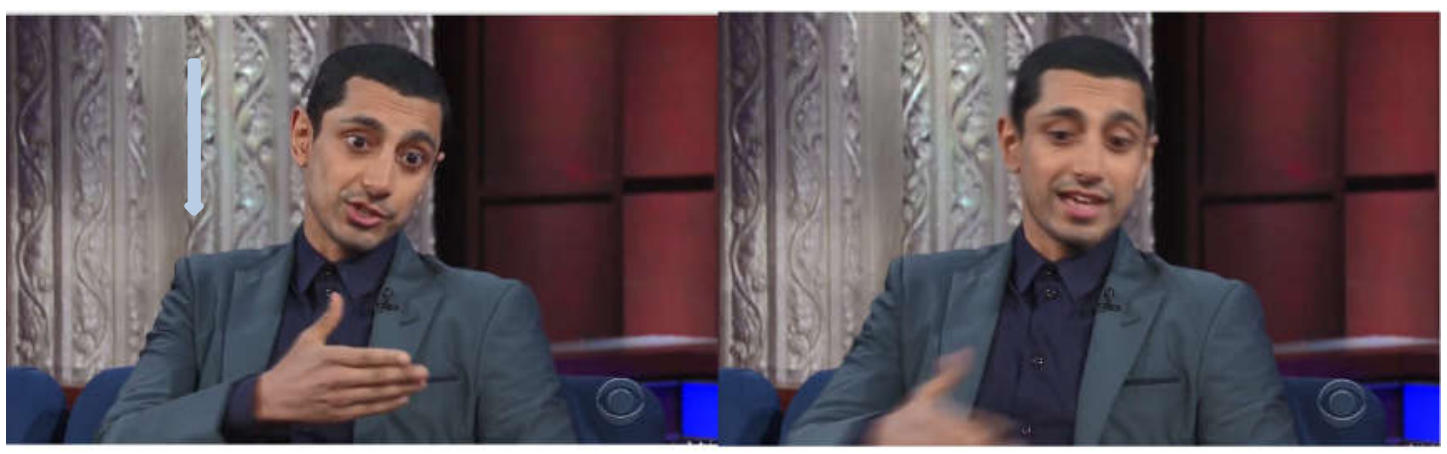

So they... ...can be really...

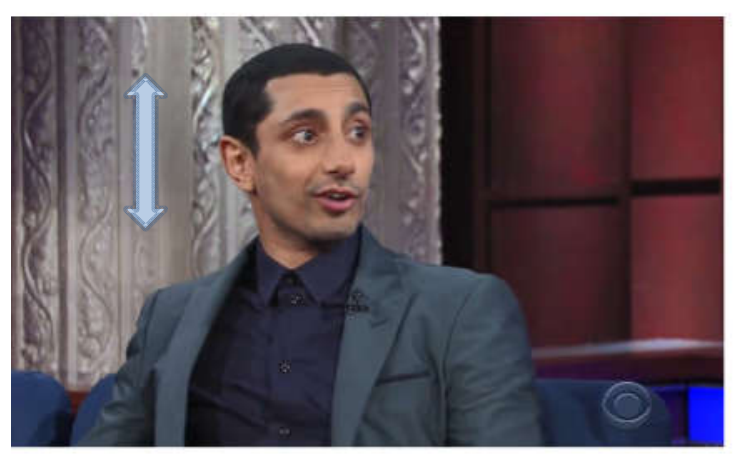

...thorough...

Figure 18. Nods in example (15). 
Riz Ahmed performs a nod co-occurring with "they", and a double nod upon "thorough". With his remark, the actor picks up on Stephen Colbert's tendentious question, agrees with the host's innuendo, and confirms it himself with his words. The nods, therefore, play a role to signal such confirmation. In addition, they loosely align with the two most prominent words in the last sentence, thus contributing, along with prosody, to information structure, as those are the two key words to comprehend the message.

Example (16) shows an instance of repeated nodding. Stephen Colbert asks Sigourney Weaver if they have started shooting the second part of the film Avatar, to which she awkwardly replies that they haven't, and that if she had said the opposite in an interview the day before, she had been wrong. It so appears that they had indeed started shooting the film, but that the information was probably under embargo, and no one was allowed to speak about it. The host then asked if they would start shooting at some point, to which the actress replied as follows:

(16) Sigourney Weaver: I'm sure we will start at some point.

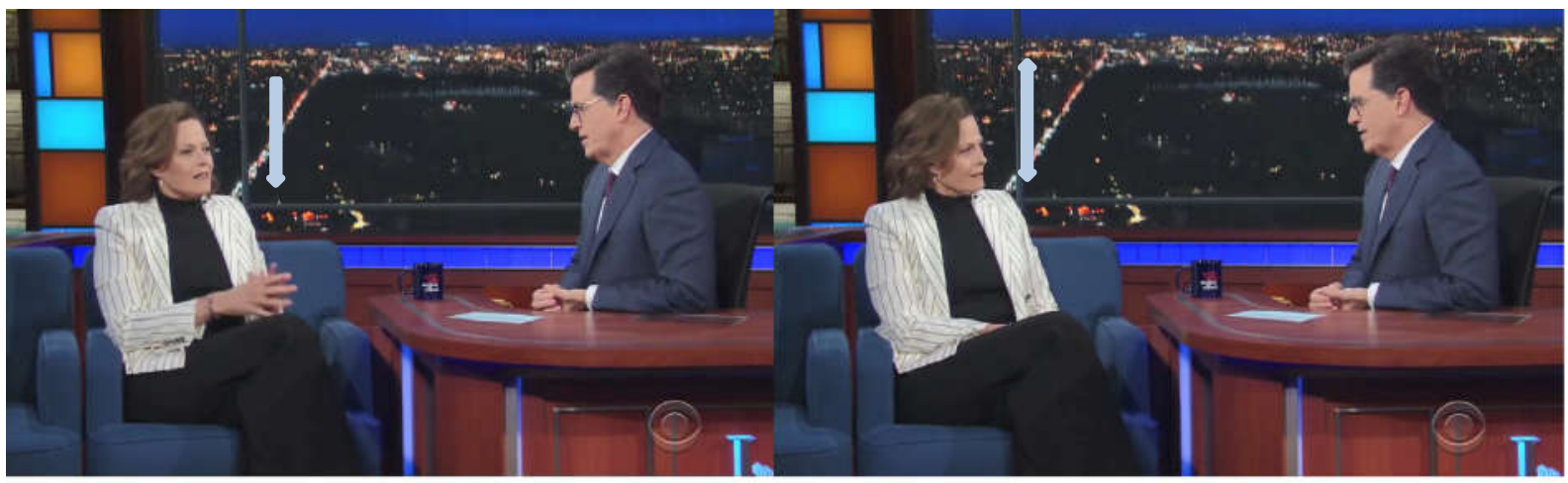

I'm sure we will... ...start...

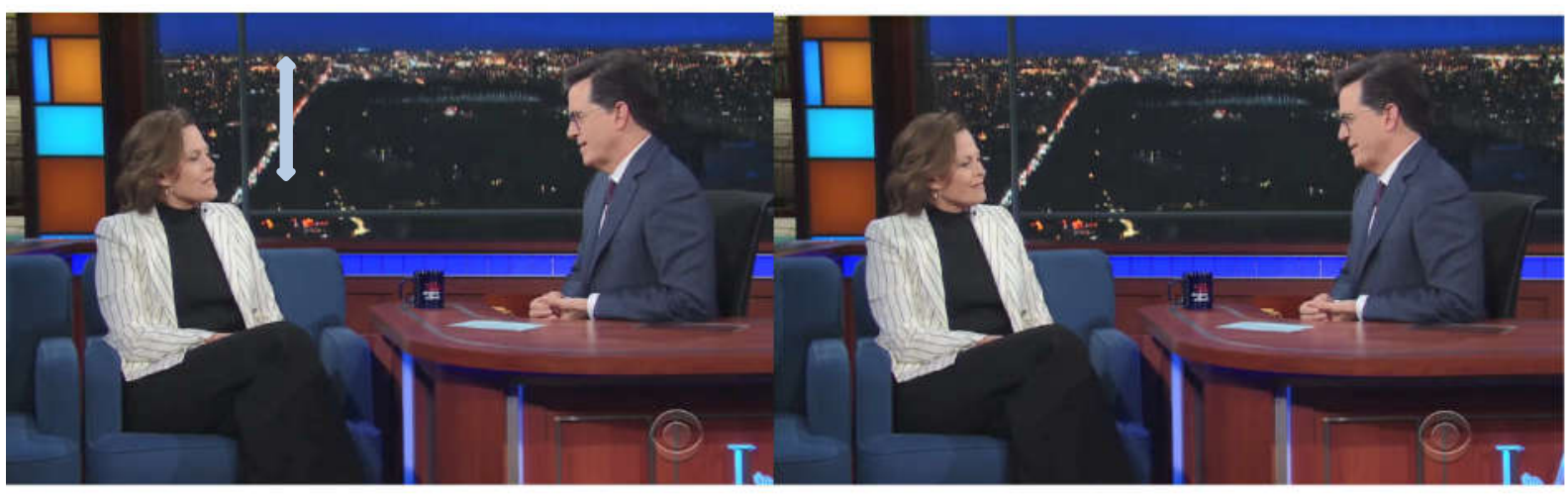

... at some point.

Figure 19. Nods in example (16).

The whole utterance is punctuated by nods, clearly signalling confirmation. Furthermore, there is a strong correlation with prosody, as the word "start" is made more salient in the statement by means of prosodic accent and also underlined by a longer nod, in which the head is kept down until Sigourney Weaver starts uttering "at some point", when her head shifts to baseline position. A last nod is performed right after the utterance is finished, which, along with gaze directed at the listener, could be taken as a signal to yield the turn. 
As seen through these examples, nodding in humour performs the same functions as in non-humorous utterances identified in previous studies (McClave 2000; Poggi et al. 2010; Swerts \& Krahmer 2010; Ishi et al. 2014). This analysis also illustrates the polysemy of gestures, even within the same instantiation, in which they can be interpreted as having different functions, e.g. information structuring and confirmation, as in example (15). In order to disentangle their meaning, gestures need always to be interpreted in the multimodal context in which they are being performed (Poggi et al. 2010; Wagner et al. 2014; Heylen 2008).

\subsection{Head shakes and head turns}

Head shakes and head turns also frequently appear in the sample, although in fewer numbers than nods and tilts. Both are performed along the same axis, with shakes involving repeated sweeps, and turns a single movement (Wagner et al. 2014). In addition, shakes differ from turns in terms of amplitude and the angle of the movement performed (Kendon 2002). Kendon (2002) argues that head shakes share a core meaning of negation, although their different instantiations can correlate with inclusivity, e.g. with words like 'everyone' or 'everything', intensification or superlative, e.g., with expressions such as 'very', 'a lot', 'exactly', etc. (C. Goodwin 1980; Schegloff 1987), uncertainty, and lexical repairs (McClave 2000; Kendon 2002). The underlying implicit notion of negation in head shakes accompanying expressions of intensification or inclusivity is justified as no exceptions are envisaged to what is being conveyed by those expressions (Kendon 2002). Interestingly, around a third of shakes occur in instances of exaggeration as a type of humour, which is consistent with this association between shakes and the expression of intensity or superlative. With regards to head turns, they are typically associated to discourse management, in terms of turn-taking and turn-yielding. They serve as signals structuring abstract spaces where to locate referents in speech (McClave 2000).

In example (17), Amy Schumer is telling about an incident she had with activists from PETA, an animal welfare organisation, who had criticised her for wearing a coat with a hood lined with coyote fur.

(17) Amy Schumer: If I made a list of the animals I care about more than coyotes [burst of laughter in the audience]. It would be a list of every animal. I don't care.

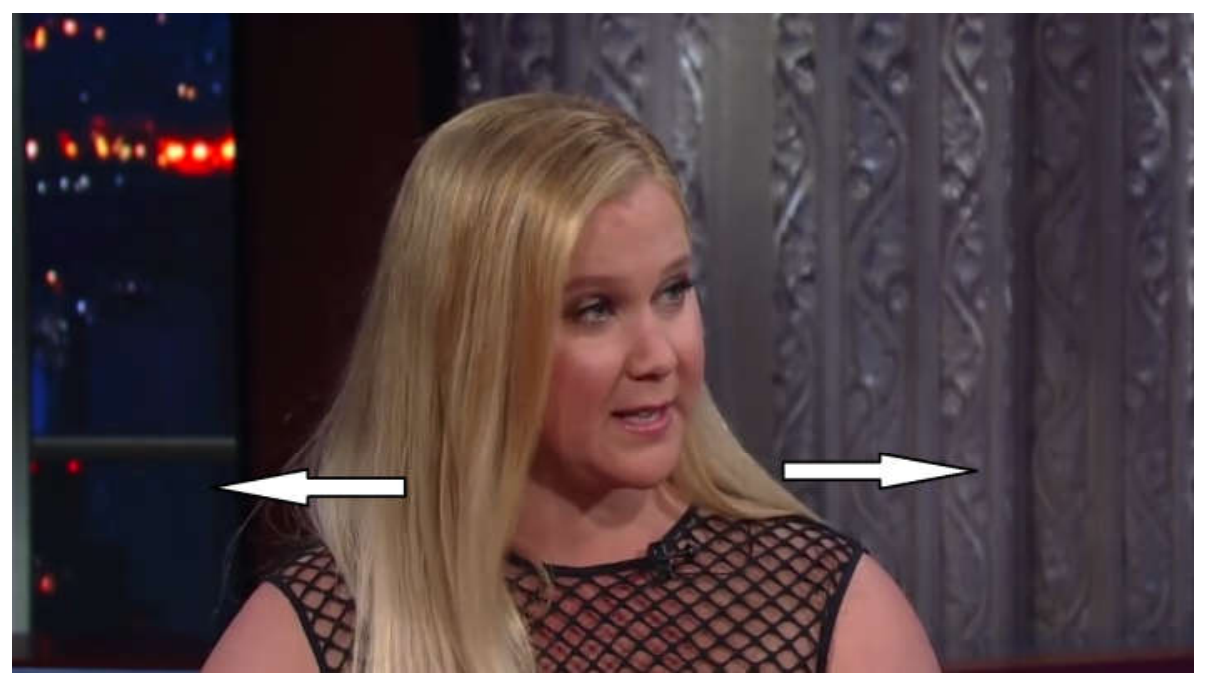

Figure 20. Shake in example (17). 
Here, Amy Schumer performs short repeated head shakes on several occasions. First, upon uttering the word 'coyotes'. This can be interpreted as the attitude of the speaker about coyotes, which is basically rejecting the idea that they should be protected. Later, while pronouncing the second part of the statement, she keeps shaking her head in short, quick, and lowamplitude movements. In this example, several of the interpretations for headshakes identified in the literature, as explained above, coincide, namely: an expression of inclusivity with 'every animal', and negation conveyed in 'I don't care'.

Another example from the same interview illustrates a turn. In this exchange, Amy Schumer is talking about the comments made by some journalists about her body, deemed to be too plump for current Hollywood beauty standards.

(18) Amy Schumer: They talk to me as if I need to be buttered to fit through a door.

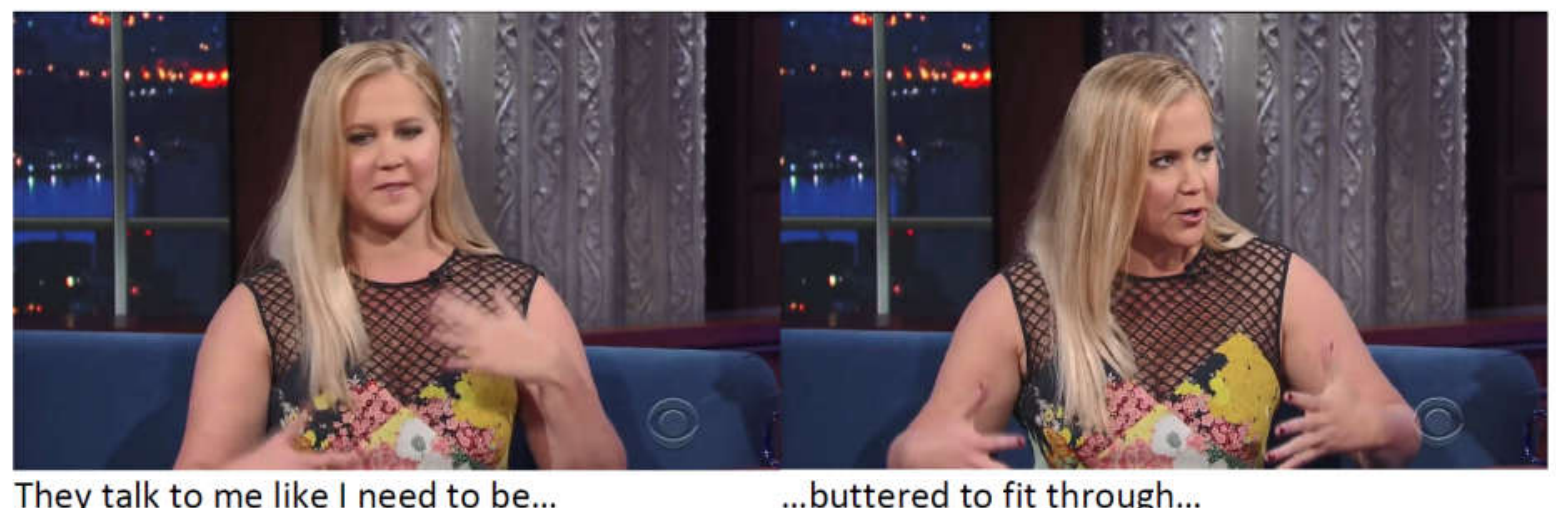

They talk to me like I need to be...

...buttered to fit through...

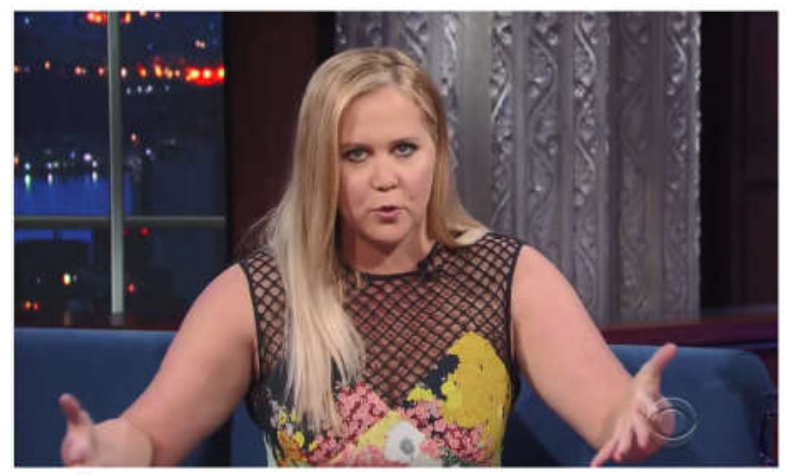

...a door.

Figure 18. Turns in example (21).

Amy Schumer performs two turns during her remark. First, upon uttering 'buttered', she turns to make eye contact with the host. I interpret this turn as seeking confirmation of the hearer's attention, as well as underlining the word 'buttered' as the one of the most relevant elements in the utterance. Then, she turns her head again upon the pronunciation of 'door'. Once again, there is a correlation with prosody in terms of what words are most prominent, which, at the same time, I believe is linked to information structure in the sentence, highlighting the most meaningful words, i.e., 'buttered', and 'door'. Furthermore, taking the latter turn along with gaze and hand gestures, I posit that it is pointing to the abstract space where the door is. As a matter of fact, she refers to the door shortly afterwards, in an utterance not taken as humorous, and she turns again to that very same space when pronouncing the word 'door'.

Let's now consider example (19), in which different gestures co-occur, among which repeated shakes and a turn. Stephen Colbert has said to Elon Musk that given that he's trying 
to do great things, he is a billionaire, and he is involved in the development of many state-ofthe art technologies, he has to be either a superhero or a supervillain, so that he has to choose one or the other. Elon Musk replies:

(19) Elon Musk: I try to do useful things.

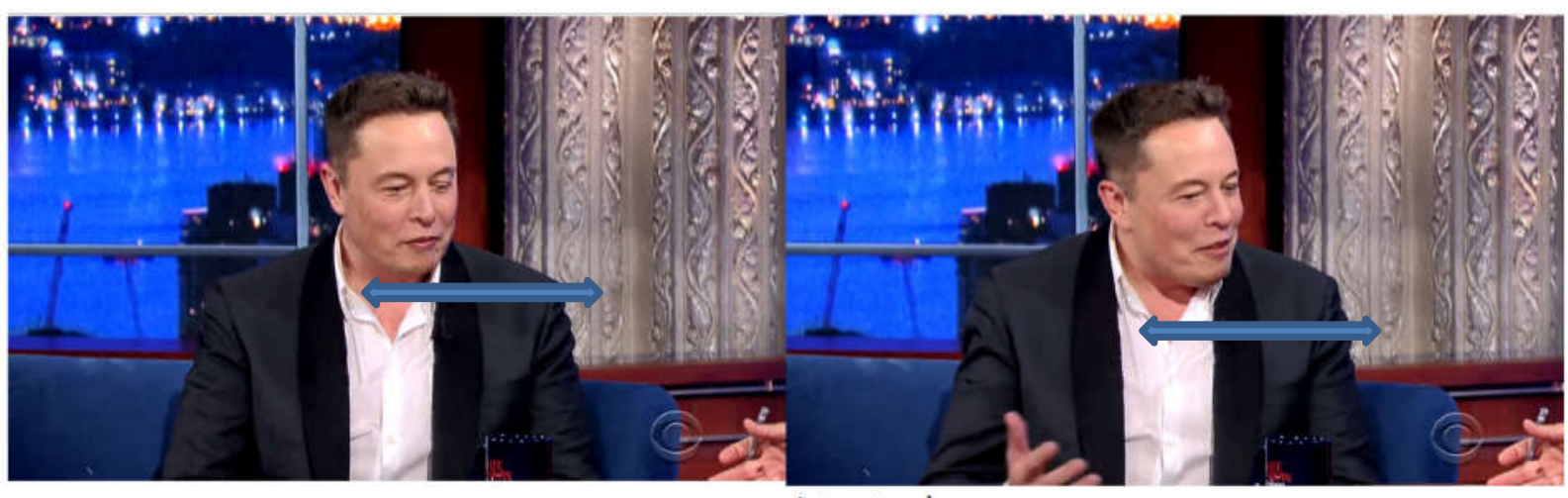

I try to do...

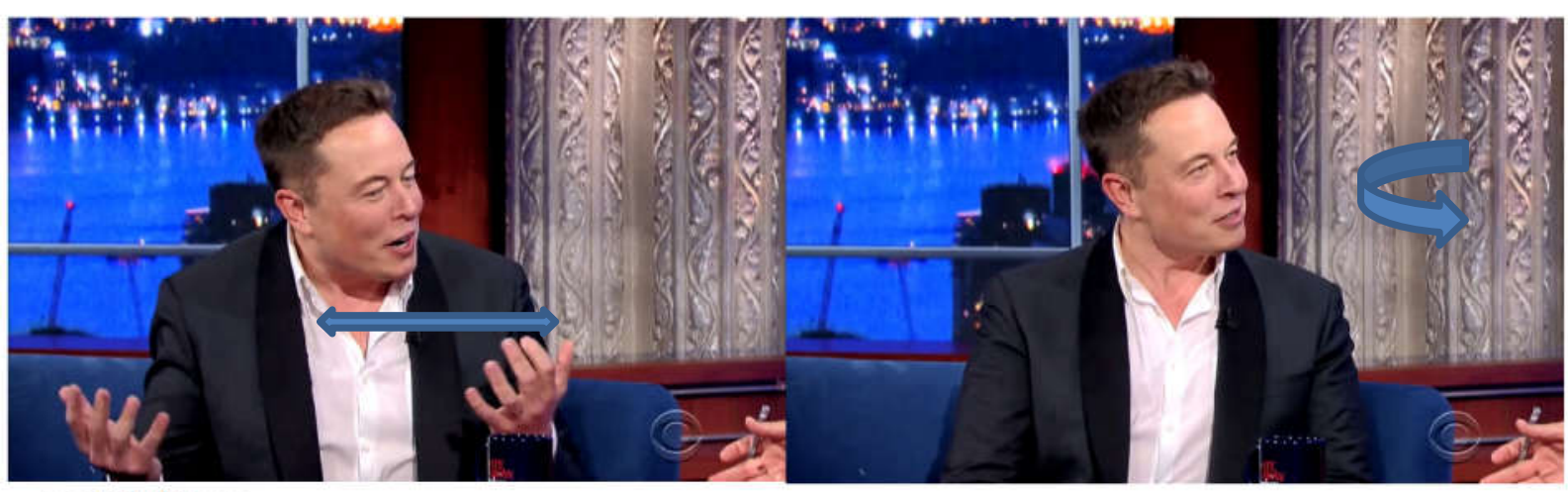

...useful things.

Figure 22. Shake and turn in example (19).

He precedes his statement with repeated head shakes that are maintained throughout, which could be interpreting as negating the idea that he is a superhero or a supervillain. Indeed, this utterance has been categorised in the sample as an example of understatement, as Elon Musk is trying to downplay the importance of what he does with regards to the idea of superhero saving the world, as portrayed by the host. In addition, Elon Musk performs a turn at the end of the statement, making eye contact with his interlocutor, while simultaneously instantiating a nod and a tilt. I believe those movements have the function of signalling the end of his remark and yielding the turn in the conversation. The nod could also be seeking approval from the interlocutor, while the tilt could also be associated to a further expression of denial or disbelief with regards to the previous host's words.

These examples further demonstrate the complexity surrounding the performance of head movements, whose analysis can certainly yield different interpretations as to what functions can be assigned and what role they are playing in any given instance of communication.

\section{Conclusion}

In light of the analysis reported above, none of the gestures co-occurring with humour that have been identified in the sample can be considered markers of humour, as they do not 
consistently co-occur with humorous utterances (Attardo, Wagner \& Urios-Aparisi, 2011). The results of the analysis conducted bear out the outcome of previous studies on these gestures in the literature (e.g. Poggi \& Pelachaud 1998; McClave 2000; Kendon 2002; Lee \& Marsella 2010; Attardo et al. 2013; Tabacaru 2014). It confirms previous findings on the meaning of gestures, which carry the same discursive, pragmatic, and semantic functions in humorous and non-humorous communication (Table 6).

Table 6. Functions of face and head movements identified in sample.

\begin{tabular}{|c|c|}
\hline Gesture & Function identified in sample \\
\hline nod & $\begin{array}{c}\text { Agreement, underliner, } \\
\text { backchannel request, } \\
\text { confirmation }\end{array}$ \\
\hline tilt & $\begin{array}{c}\text { Gestural triggers in sarcasm and } \\
\text { anecdote, expression of } \\
\text { disbelief, information structure, } \\
\text { rejection }\end{array}$ \\
\hline raised eyebrows & $\begin{array}{c}\text { Information structure, } \\
\text { underliner, gestural trigger in } \\
\text { irony and hyper-understanding }\end{array}$ \\
\hline turn & $\begin{array}{c}\text { Change in narrator, change in } \\
\text { viewpoint, turn yielding }\end{array}$ \\
\hline shake & $\begin{array}{c}\text { Rejection, inclusivity } \\
\text { Frame turn as humorous or } \\
\text { ironical, face-saving, affective } \\
\text { display }\end{array}$ \\
\hline smile &
\end{tabular}

The present study reaffirms the importance of conducting research on spontaneous communication, given that the production of multimodal cues is heavily influenced by the participants and context of communication. The context in which communication occurs, and the participants in the communicative event exert an influence in the amount of multimodal cues we produce, e.g. nodding more with less familiar interlocutors, or repressing certain face gestures when confronted with authoritative figures (Cvejic et al. 2012; Ishi et al. 2014; Wagner et al. 2014). As a result, research outcomes may differ considerably in staged settings, where a wide audience is reached out to.

In sum, no multimodal behaviour specific to humour that sets it apart from non-humorous communication has been found. Instead, speakers just recruit and elicit any modality at their disposal, fully exploiting related affordances, to try to convey their message in the most effective manner, regardless of whether that message happens to be humorous or not. The gestures identified are not specific to humorous communication; they are used as multimodal tools by speakers and hearers in communication at large. The analysis conducted proves that not only will the interplay between different modalities have an impact on how an utterance may be interpreted, but also the overlap of co-occurring gestures, even from the same modality. In light of the above, it is clear that gestures cannot just be taken as elements merely punctuating speech, but as part of a "multimodal construction in which the different modalities of expression available are deployed by the speaker in the course of building a unit of expression according to the rhetorical needs of the interactive moment" (Kendon 2002, 147).

\section{Acknowledgements}

I would like to express my utmost gratitude to Dr. Juan J. Colomina-Almiñana for his invaluable advice and guidance throughout my research. My appreciation goes as well to Dr. 
María Sol Velasco-Sacristán for her thesis supervision work. I also thank the anonymous reviewers for their insightful comments on early versions of this article. Needless to say, any shortcomings therein remain my sole and full responsibility.

\section{References}

Adami, E. (2016). 'Multimodality', in García, O., Flores, N. \& Spotti, M. (eds.), Oxford Handbook of Language and Society. Oxford: Oxford University Press.

Altorfer, A., Jossen, S., Würmle, O., Käsermann, M. L., Foppa, K. \& Zimmermann, H. (2000). 'Measurement and meaning of head movements in everyday face-to-face communicative interaction'. Behaviour Research Methods Instruments and Computers 32 (1), pp. 17-32.

Attardo, S. (1994). Linguistic Theories of Humour. Berlin: Walter de Gruyter.

Attardo S. (2000). 'Irony markers and functions: Toward a goal-oriented theory of irony and processing'. Rask. Internationalt Tidsskrift for Sprog og Kommunikation, 12, pp. 3-20.

Attardo, S., Eisterhold, J., Hay, J. \& Poggi, I. (2003). 'Multimodal markers of irony and sarcasm'. Humour 16(2), pp. 243-260.

Attardo S., Pickering, L. \& Baker, A. (2011). 'Prosodic and multimodal markers of humour in conversation', in Attardo, S., Wagner, M. \& Urios-Aparisi, E. (eds.), Prosody and Humour. Amsterdam/Philadelphia: John Benjamins, pp. 224-247.

Attardo, S., Wagner, M. \& Urios-Aparisi, E. (2011). 'Prosody and humour'. Pragmatics \& Cognition 19(2), pp. 189-201.

Attardo, S., Pickering, L., Lomotey, F. \& Menjo, S. (2013). 'Multimodality in conversational humour'. Review of Cognitive Linguistics, 11(2), pp. 402-416.

Brône, G. (2008). 'Hyper- and misunderstanding in interactional humour'. Journal of Pragmatics, 40(12), pp. 2027-2061.

Castelfranchi, C. \& Poggi, I. (1990). 'Blushing as a discourse: was Darwin wrong?', in Crozier, R. (ed.), Shyness and Embarrassment. Perspective from Social Psychology. Cambridge: Cambridge University Press, pp. 230-251.

Cavé, C., Gua, I., Bertrand, R., Santi, S., Harley, F. \& Espesser, R. (1996). 'About the relationship between eyebrow movements and F0 variations'. International Conference on Spoken Language Processing, pp. 2175-2178.

Cienki, A. (2013). 'Cognitive Linguistics: Spoken language and gesture as expressions of conceptualization', in Müller, C., Cienki, A., Ladewig, S., McNeill, D. \& Teßendorf. S. (eds.), Body-Language-Communication: An International Handbook on Multimodality in Human Interaction (Vol. 1). Berlin: de Gruyter Mouton, pp. 182-201.

Cvejic, E., Kim, J. \& Davis, C. (2010). 'Prosody off the top of the head: Prosodic contrasts can be discriminated by head motion'. Speech Communication 52(6), pp. 555-564.

Darwin, C. (1872). The Expression of the Emotion in Man and Animals. London: John Murray.

Debras, C. \& Cienki, Al. (2012). 'Some uses of head tilts and shoulder shrugs during human interaction, and their relation to stancetaking'. 2012 International Conference on Privacy, Security, Risk and Trust and 2012 International Conference on Social Computing, Amsterdam, pp. 932-937. doi: 10.1109/SocialCom-PASSAT.2012.136

Drahota, A., Costall, A. \& Reddy, V. (2008). 'The vocal communication of different kinds of smile'. Speech Communication 50(4), pp. 278-287.

DsNet Corp. (2017). aTubeCatcher Version 3.8.9325, retrieved 1 July 2017 from http://www.atube.me 
Eisterhold, J., Attardo, S. \& Boxer, D. (2006). 'Reactions to irony in discourse: evidence for the least disruption principle'. Journal of Pragmatics 38, pp. 1239-1256.

Ekman, P. (1979). 'About brows-Emotional and conversational signals', in von Cranach, M. K., Foppa, W., Lepenies \& Ploog, D. (eds.), Human Ethology. Cambridge: Cambridge University Press, pp. 169-248.

Ekman, P., (1982). Emotion in the Human Face. New York: Cambridge University Press.

Ekman, P. \& Friesen, W.V. (1971). 'Constants across cultures in the face and emotion'. Journal of Personality and Social Psychology 17(2), pp. 124-129.

ELAN (Version 5.0.0-beta) [Computer software]. (2017, April 18). Nijmegen: Max Planck Institute for Psycholinguistics. Retrieved from https://tla.mpi.nl/tools/tla-tools/elan/

El Kaliouby, R. \& Robinson, P. (2004). 'Real-time inference of complex mental states from facial expressions and head gestures', in Kiskanin, B., Pavlovic, P. \& Huang, T. (eds.), Real-Time Vision for Human-Computer Interaction. Boston: Springer, pp. 181-200.

Feyaerts, K. (2013). 'Tackling the complexity of spontaneous humorous interaction: An integrated classroom-modelled corpus approach', in Ruiz Gurillo, L. \& Alvarado Ortega, M. B. (eds.), Pragmatics \& beyond New Series (Vol. 231). Amsterdam: John Benjamins, Publishing Company, pp. 243-268.

Flamson, T., Bryant, G. \& Barret, H. (2011). 'Prosody in spontaneous humour'. Pragmatics \& Cognition 19(2), pp. 189-201.

Flecha-García, M. L. (2010). 'Eyebrow raises in dialogue and their relation to discourse structure, utterance function and pitch accents in English'. Speech Communication 52(6), pp. 542-554.

Forceville, C. (2016). 'Mixing in pictorial and multimodal metaphors?', in Gibbs R. W. (ed.), Metaphor in Language, Cognition, and Communication, Vol. 6, Chapter 11. Amsterdam: John Benjamins Publishing Company, pp. 223-240.

Gironzetti, E. (2017). 'Prosodic and multimodal markers of humour', in Attardo S. (ed.), The Routledge Handbook of Language and Humour. London: Routledge, pp. 235-254.

Gironzetti, E. \& Menjo, S. (2014). 'Smiling as a discourse marker of humour'. Proceedings from 2nd Conference of the American Pragmatics Association (AMPRA). Los Angeles: University of California.

Gironzetti, E., Attardo, S., Pickering, L., Huang, M., Menjo, S. \& Zhang, Y. (2015). 'Multimodal analysis of humour in conversation'. Proceedings from the 27th Conference of the International Society of Humour Studies (ISHS). Oakland: Holy Names University.

Goodwin, C. (1980). 'Restarts, pauses, and the achievement of a state of mutual gaze'. Sociological Inquiry pp. 272-302.

Guaitella, I., Santi, S., Lagrue, B. \& Cave, C. (2009). 'Are eyebrow movements linked to voice variations and turn-taking in dialogue? An experimental investigation'. Language and Speech 52(2/3), pp. 207-222.

Hadar, U., Steiner, T.J., Grant, E.C. \& Clifford Rose, F. (1983). 'Kinematics of head movements accompanying speech during conversation'. Human Movement Science 2, pp. $35-46$.

Hadar, U., Steiner, T.J. \& Grant, E.C. (1984). 'The timing of shifts of head postures during conversation'. Human Movement Science 3, pp. 237-245.

Hadar, U., Steiner, T.J. \& Clifford Rose, F. (1985). 'Head movement during listening turns in conversation'. Journal of Nonverbal Behaviour 9, pp. 214-228.

Hay, J. (2001). 'The pragmatics of humour support'. Humour 14(1), pp. 55-82.

Heylen, D. (2008). 'Listening heads', in Wachsmuth, I. \& Knoblich, G. (eds.), Modelling Communication. Berlin/Heidelberg: Springer-Verlag, pp. 241-259. 
Hoskin, J. (director), Colbert, S., Spyra, J., Stack, B. \& Dinello, P. (writers). (2015-). The Late Show with Stephen Colbert [Television show]. Retrieved from https://www.youtube.com/channel/UCMtFAi84ehTSYSE9XoHefig

Holt, E. \& Glenn, P.J. (2013). Studies of Laughter in Interaction. London: Bloomsbury Academy.

Ikeda, K. \& Bysouth, D. (2013). 'Laughter and turn-taking: Warranting next speakership in multiparty interactions', in Holt, E. \& Glenn, P. (eds.), Studies of Laughter in Interaction. London: Bloombsbury Academic, pp. 36-64.

Ishi, C. T., Ishiguro, H. \& Hagita, N. (2014). 'Analysis of relationship between head motion events and speech in dialogue conversations'. Speech Communication 57, pp. 233-243.

Jefferson, G., Sacks, S. \& Schegloff, E. A. (1987). 'Notes on laughter in the pursuit of intimacy', in Button, G. \& Lee, J. R. E. (eds.), Talk and Social Organisation. Clevedon: Multilingual Matters, pp.152-205.

Kendon, A. (1980). 'Gesticulation and speech: two aspects of the process of utterance', in R. Key M. (ed.), The Relationship of Verbal and Nonverbal Communication. The Hague: Mouton and Co, pp. 207-227.

Kendon, A. (2002). 'Some uses of the headshake'. Gesture 2(2), pp. 147-182.

Kendon, A. (2004). Gesture: Visible Action as Utterance. Cambridge, England: Cambridge University Press.

Kim, J., Cvejic, E. \& Davis, C. (2014). 'Tracking eyebrows and head gestures associated with spoken prosody'. Speech Communication 57, pp. 317-330.

Kousidis, S., Malisz, Z., Wagner, P. \& Schlangen, D. (2013). 'Exploring annotation of head gesture forms in spontaneous human interaction' in TiGeR 2013, Tilburg Gesture Research Meeting.

Krahmer, E. \& Swerts, M. (2007). 'The effects of visual beats on prosodic prominence: Acoustic analyses, auditory perception and visual perception'. Journal of Memory and Language 57(3), pp. 396-414.

Kress, G. \& van Leeuwen, T. (2001). Multimodal Discourse: The Modes and Media of Contemporary Communication. London: Arnold. New York: Oxford University Press.

Lee, J. \& Marsella, S. (2006). 'Nonverbal behaviour generator for embodied conversational agents'. Proceedings of Sixth International Conference on Intelligent Virtual Agents (IVA), Marine del Rey, USA, August 21-23, pp. 243-255.

Lee, J. \& Marsella, S. (2010). 'Predicting speaker head nods and the effects of affective information'. IEEE Transactions on Multimedia 12(6), pp. 552-562.

Maynard, S. K. (1987). 'Interactional functions of a nonverbal sign: Head movement in Japanese dyadic casual conversation'. Journal of Pragmatics 11(5), pp. 589-606.

McClave, E. (2000). 'Linguistic functions of head movements in the context of speech'. Journal of Pragmatics 32, pp. 855-878.

McNeill, D. (1992). Hand and Mind: What Gestures Reveal about Thought. Chicago/London: The University of Chicago Press.

Mondada, L. (2013). 'Conversation analysis: Talk and bodily resources for the organisation of social interaction', in Müller, C., Cienki, A., Ladewig, S., McNeill, D. \& Teßendorf, S. (eds.), Body-Language-Communication: An International Handbook on Multimodality in Human Interaction (Vol. 1). Berlin: de Gruyter Mouton, pp. 228-226.

Morreall, J. (1983). Taking Laughter Seriously. New York: State University of New York Press.

Norrick, N. (1993). Conversational Joking. Bloomington: Indiana University Press.

Norris, S. (2013). 'Multimodal (inter)action analysis: An integrative methodology', in Müller, C., Cienki, A., Ladewig, S., McNeill, D. \& Teßendorf, S. (eds.), Body-Language- 
Communication: An International Handbook on Multimodality in Human Interaction (Vol. 1). Berlin: de Gruyter Mouton, pp. 275-286.

Parrill, F. (2012). 'Interactions between discourse status and viewpoint in co-speech gesture', in Dancygier, B. \& Sweetser E. (eds.). Viewpoint in Language: A Multimodal Perspective. Cambridge: Cambridge University Press, pp. 97-112. doi:10.1017/CBO9781139084727.008

Pelachaud, C., Badler, N. \& Steedman, M. (1996). 'Generating facial expressions for speech'. Cognitive Science 20, pp. 1-46.

Poggi, I. \& Pelachaud, C. (1998). 'Performative faces'. Speech Communication 26, pp. 5-21.

Poggi, I., D’Errico, F. \& Vincze, L. (2010). 'Types of nods. The polysemy of a social signal'LREC. $\quad$ Retrieved $\quad$ August, $\quad 15 \quad 2018$ from https://pdfs.semanticscholar.org/ca9d/97fb5292e2d33e77fab7082832e7926174c6.pdf

Provine, R. (2000). Laughter. A Scientific Investigation. London/New York: Penguin Random House.

Smoski, M.J. \& Bachorowski, J.A. (2003). 'Antiphonal laughter between friends and strangers'. Cognition \& Emotion 17, pp. 327-340.

Stec, K. (2012). 'Meaningful shifts: A review of viewpoint markers in co-speech gesture and sign language'. Gesture 12(3), pp. 327-360. doi: https://doi.org/10.1075/gest.12.3.03ste

Swerts, M. \& Krahmer, E. (2008). 'Facial expression and prosodic prominence: Effects of modality and facial area'. Journal of Phonetics 36(2), pp. 19-238.

Swerts, M. \& Krahmer, E. (2010). 'Visual prosody of newsreaders: Effects of information structure, emotional content and intended audience on facial expressions'. Journal of Phonetics 38, pp. 197-206.

Tabacaru, S. (2014). Humorous implications and meanings: A multi-modal approach to sarcasm in interactional humour. Université Charles de Gaulle - Lille 3, Doctoral dissertation. Retrieved August 15, 2018 from http://www.theses.fr/2014LIL30015

Tabacaru, S. \& Lemmens, M. (2014). 'Raised eyebrows as gestural triggers in humour: The case of sarcasm and hyper-understanding'. European Journal of Humour Research 2(2), pp. 11-31.

Veale, T., Feyaerts, K. \& Brône, G. (2006). 'The cognitive mechanisms of adversarial humour'. Humour 19(3), pp. 305-338. doi: 10.1515/HUMOR.2006.016

Wagner, P., Malisz, Z. \& Kopp, S. (2014). 'Gesture and speech in interaction: An overview'. Speech Communication 57, pp. 209-232.

Weeks, M. (2016). 'The enigma of solitary laughter'. European Journal of Humour Research 4(3), pp. 76-87. 